\title{
A REVIEW ON VIBRATION-BASED STRUCTURAL HEALTH MONITORING WITH SPECIAL EMPHASIS ON COMPOSITE
}

\section{MATERIALS}

Corresponding Author:

\author{
Nuno M. M. Maia \\ (Associate Professor)
}

Instituto Superior Técnico, Technical University of Lisbon

Department of Mechanical Engineering

Av. Rovisco Pais, 1049-001 Lisboa, Portugal

$$
\begin{gathered}
\text { Telephone: + } 351218417454 \\
\text { Fax: + } 351218417915 \\
\text { e-mail: nmaia@dem.ist.utl.pt }
\end{gathered}
$$




\title{
A REVIEW ON VIBRATION-BASED STRUCTURAL HEALTH
}

\section{MONITORING WITH SPECIAL EMPHASIS ON COMPOSITE}

\author{
MATERIALS \\ Montalvão $^{1}$, D., Maia ${ }^{2}$, N. M. M., Ribeiro ${ }^{2}$, A. M. R. \\ ${ }^{l}$ Department of Mechanical Engineering, Escola Superior de Tecnologia, Polytechnic Institute of Setúbal \\ Campus do IPS, Estefanilha, 2910-761 Setúbal, Portugal \\ E-mail:dmontalvao@est.ips.pt \\ ${ }^{2}$ Department of Mechanical Engineering, Instituto Superior Técnico, Technical University of Lisbon \\ Av. Rovisco Pais, 1049-001 Lisboa, Portugal \\ E-mail: nmaia@dem.ist.utl.pt
}

\begin{abstract}
Structural health monitoring and damage detection techniques are tools of great importance namely in the offshore, civil, mechanical and aeronautical engineering communities, either due to safety reasons or to the economical benefits it may bring. The need for detecting damage in complex structures has led to the development of a vast amount of techniques, in particular those based upon structural vibration analysis. In the present article, some of the latest advances in Structural Health Monitoring and Damage Detection have been covered, with an emphasis on composite structures, given the fact that this kind of materials have currently a wide range of engineering applications.
\end{abstract}

\section{FOREWORD}

It should be noted that this review is not intended to be a general, all-encompassing review about structural health monitoring $(S H M)$; it was planned as the starting point for a study focusing on damage detection, localization and assessment on certain kind of structures. Thus, the line of thought behind the search and the structure of this review is a result of objectives beyond the scope of the paper itself. Nevertheless, it was considered that, once the above was understood, an updated synopsis such as this could also be useful for other researchers in the same field.

\section{INTRODUCTION}


Vibration-based $S H M$ and damage detection is a field of study of great interest. Important advances in this field are described in Doebling et al. (1996**), Doebling et al. (1998**) and Sohn et al. (2003) which present very comprehensive surveys covering the period until early 2002. Many of the works cited in these surveys are still state-of-the-art, motivating their inclusion in this work. Therefore, all the citations common to Doebling et al. (1996**) and Sohn et al. (2003) are herein identified with, respectively, * and ** accompanying the year of publication.

Other reviews may bring insight in more specific branches of damage detection and SHM. For example, a state-of-the-art overview on rotating machinery monitoring is given by Randall (2002). More recently, Carden and Fanning (2004) presented a review covering structural engineering related aspects. Uhl and Mendrok (2004) discuss the applicability of modal model-based methods in structural diagnosis. Farrar et al. (2004) present a brief, yet comprehensive overview of nonlinear system identification techniques used for damage-sensitive feature extraction from measured data.

In the present paper, special attention will be given to methods in which composite materials and structures are used as case studies. Nevertheless, mostly because of the huge amount of methods found in the literature, and considering what was said in the Foreword, many damage detection and SHM techniques will not be explored, though punctually addressed in some cases, such as rotating machinery, online SHM and monitoring systems, updating, sensitivity-based methods (which are widespread in model updating), non-linear systems, wireless sensing, civil infrastructures, joints and couplings, conditioning, chaotic time series excitation, etc. Therefore, one has decided to include methods based on natural frequencies, frequency response functions $(F R F s)$, mode shapes, mode shape and FRF curvatures, auto-regressive moving average (ARMA) family models, dynamic flexibility, modal strain energy, transmissibility, damping, impedance, Lamb waves, time-frequency analysis, Hilbert transforms, principal component analysis $(P C A)$ and singular value decomposition $(S V D)$, neural networks, instrumentation and others.

A general definition of damage is given by Sohn et al. (2003) as “...changes introduced into a system that adversely affect its current or future performance. Implicit in this definition is the concept that damage is not meaningful without a comparison between two different states of the system, one of which is assumed to represent the initial, and often undamaged, state." As examples, one may have a structural crack (stiffness change), bridge pillar silting (boundary condition change), counterweight balancing loss (mass change) or looseness in a bolted joint (connectivity change) (Maia (2001)).

The need for detecting damage in complex structures has motivated the development of techniques based upon variations in the structural dynamic behavior. For instance, the method to monitor the condition of train wheels is used today as it was 100 years ago: one 'modal specialist' walks along the train cars hitting the wheels with a hammer and listening to their response (Maia (2001)). In conditioning maintenance, vibration is without any doubt the most straightforward indicator of a machine state when compared to other indicators, such as temperature, pressure, flow or tribology features (Wowk (1991)). In another field of application, Vescovo and Fregolent (2005) use an acoustic, non-invasive experimental technique to assess the partial detachment of plaster portions in artistic frescoes. It is even argued by Bonfiglioli et al. (2005) that the impact of monitoring and assessing the health state of infrastructures seems to be one of the largest industries in the world.

The main idea behind damage detection techniques based on structural dynamic changes is the fact that the modal parameters (natural frequencies, mode shapes and modal damping) are functions of the physical parameters (mass, stiffness and damping) and thus it is reasonable to assume that the existence of damage leads to changes in the modal properties of the structure.

According to Doebling et al. (1996**), ideally, a robust damage detection scheme should be able to identify damage at a very early stage, locate the damage within the sensor resolution being used, provide some estimate for the damage extension or severity and to predict the remaining useful life of the structural component where damage has been identified. The method should also be well suited to automation, and should be independent from human judgment and ability.

Betti (2005) points out that no single approach is appropriate for all situations, making the following basic distinctions between each approach: linear $v s$ non-linear, output only $v s$ input/output, on-line $v s$ 
off-line, time domain $v s$ frequency domain, parametric $v s$ non-parametric and time varying $v s$ timeinvariant.

Operational and environmental conditions, such as temperature, humidity, loads and boundary conditions should also be addressed, since in many cases they can 'hide' changes strictly caused by damage. For example, Farrar et al. (1994****), having done several measurements on the I-40 bridge over the Rio Grande in Albuquerque in the state of New Mexico in the USA, observed that temperature plays a major role in the dynamic properties of the bridge. They introduced four different levels of damage by gradually cutting one of the bridge girders, corresponding to a loss of stiffness. However, instead of what would be expectable, they noticed an increase in the fundamental frequency for the first two damage cases, concluding that such results were mainly due to temperature changes and temperature gradients in the bridge. Many other researchers, such as Woon and Mitchell (1996a) (1996b), Andersen et al. (1997), Alampalli (2000), Peeters and De Roeck (2000), Kullaa (2002), De Roeck and Degrauwe (2005a), Steenackers and Guillaume (2005) or Yan et al. (2005a) (2005b) address the effects of the environmental or operational conditions in Structural Health Monitoring. Woon and Mitchell (1996a) study the sensitivity of the natural frequencies to the relative humidity, but they conclude that it has little significance when compared to the temperature influence. Cawley $\left(1997^{* *}\right)$ uses an analytical model of a cantilevered beam to compare the effect of crack formation to the effect of beam length in the natural frequencies, observing that thermal expansion (simulated by changes in the beam length) has more significant effects on the natural frequencies than cracks. Kullaa (2002) tries to eliminate the environmental influences in modal parameters, using an approach based on factor analysis, in which it is assumed that there exist a set of common factors with effects on the modal features that can be subtracted from the observations.

\subsection{Damage Detection Philosophy}

Rytter $\left(1993^{* * * *}\right)$ introduced a damage state classification system which has been very well accepted by the community dealing with damage detection and SHM. Following these lines, the damage state is described by answering the following questions (Sohn et al. (2003)):

1. Is there damage in the system? (existence)

2. Where is the damage in the structure? (location)

3. What kind of damage is present? (type)

4. How severe is the damage? (extension)

5. How much useful life remains? (prognosis)

Generally, damage type and extension identification require the prior knowledge of the structural behavior when each of the possible expected failure modes are present for future correlation with experimental data, which normally is achieved by resorting to analytical models. For example, in operational monitoring, the modal parameters of the damaged structure must be compared to the parameters of the structure in its undamaged state, to what is called global diagnostics. Once damage existence is detected, the use of a model of the structure in a damaged state may be used to detect the damage location, to what is called local diagnosis (Uhl and Mendrok (2004)).

Some difficulties may be encountered in the practical application of modal models, such as the knowledge of excitations and loads during machine operation, with several sources and with unknown distribution along the system. However, several output-only based modal identification techniques can be found in the literature, for example, in Guillaume et al. (1999), Parloo et al. (2002a), Brincker and Andersen (2003a), Brincker et al. (2003b), Mevel and Goursat (2004), Rodrigues et al. (2004) or Galvin and Dominguez (2005).

Prognosis, which is traditionally related to fracture mechanics and fatigue, is starting to be brought up by the modal analysis community as a field of interest, as seen in Farrar et al. (2003**). 


\subsection{The Monitoring Process}

The monitoring process involves the observation of a system during long periods of time, using samples of experimental data acquired periodically with adequate sensors. It also involves sensitivity feature extraction and statistical correlations to determine the actual 'health' of the system. Farrar et al. (2001) and Sohn et al. (2003) acknowledge the problem of damage detection in a context of a statistical pattern recognition paradigm. Along these lines, one may describe this paradigm as a fourstep process:

1. Operational evaluation.

2. Data acquisition, fusion, and cleansing.

3. Feature extraction and information condensation.

4. Statistical model development for feature discrimination.

Sections 1.2.1 to 1.2.4 are mainly based on the very comprehensive survey of Sohn et al. (2003).

\subsubsection{OPERATIONAL EVALUATION}

Operational evaluation answers questions related to the damage detection system implementation, dealing with economical issues, possible failure modes, operational and environmental conditions and dada acquisition related limitations. As an example, Aktan et al. (2000**) present and discuss the prerequisite issues to creating a successful monitoring program.

Ruotolo and Surace $\left(1997^{* *}\right)$ develop one of the first works that explicitly address the possibility of having multiple baseline configurations, proposing a technique to distinguish between changes caused by working conditions and damage, based on the singular value decomposition (SVD).

More recently, e.g. Vanlanduit et al. (2005) also use a SVD based version to detect damage in structures subjected to different operational conditions, in respect to different working excitation levels, geometrical uncertainties and surface treatments.

\subsubsection{DATA ACQUISITION, FUSION AND CLEANSING}

Data acquisition is concerned with the data type quantities to be measured, the type and quantity of sensors to be used, the locations where these sensors are to be placed, sensor resolution, bandwidth, and hardware. This part of the process is application specific and heavily dependent on economical aspects. Another consideration is the periodicity for data acquisition. For instance, if a fatigue crack growth is to be monitored, than it is required that the data be measured in an almost continuous way. On the other hand, if measurements are to be made under varying operational and environmental conditions, data normalization helps distinguishing between signal changes caused by operational and environmental conditions from those caused by damage. Sohn et al. $\left(2001 \mathrm{a}^{* *}\right)$ observed that the natural frequency of a bridge over the Alamosa canyon in the state of New Mexico in the USA suffered $5 \%$ deviations over a 24 hour period due to temperature variations.

Sohn et al. (2003) acknowledged that, according to Klein (1999**), data fusion appeared as a result of defense organizations attempting to formalize procedures for integrating information from diverse sources, with the purpose of determining battlefield situations and preventing threats. Data fusion, as a discipline of $S H M$, is the ability to integrate data acquired from the various sensors in the measurement chain.

Data cleansing is the process of selecting data amongst the multitude of information, i.e., to accept for or to reject from the feature selection process. 


\subsubsection{FEATURE EXTRACTION AND INFORMATION CONDENSATION}

The field of damage detection, inside the lines of the paradigm defined by Farrar et al. (2001) and Sohn et al. (2003), which has received the highest attention is feature extraction. Feature extraction is the process of identifying damage sensitive properties, which allows one to distinguish between the damaged and undamaged structural states.

Information condensation becomes advantageous and necessary, particularly if comparisons are to be made between data obtained during the life cycle of a system. Condensation may be seen as a form of data fusion.

The evolution that the philosophy of damage detection and SHM has suffered in the last ten years can be well understood when one compares both the surveys of Doebling et al. (1996**) and Sohn et al. (2003). In the first one, the statistical pattern recognition paradigm, around which the second one was written, was not even mentioned. By that time the concepts of operational evaluation, data acquisition, fusion and cleansing and statistical model development for features discrimination were matters whose relevance seemed not to be noteworthy of an exclusive and directed research, and when addressed, were done as taking part of the feature extraction process.

\subsubsection{STATISTICAL MODEL DEVELOPMENT FOR FEATURE DISCRIMINATION}

This is the part of the SHM process that has received the least attention until the end of the last century. When data are available from both the undamaged and damaged structure, the statistical pattern-recognition algorithms fall into the general classification referred to as supervised learning. Unsupervised learning refers to the class of algorithms that are applied to data not containing examples from the damaged structure (obtained, for instance, from models) (Sohn et al. (2003)).

An important issue in the development of statistical models is to establish the model features sensitivity to damage and to predict false damage identification. In this context, one may have either false-positives, in which damage is identified though it did not happen, or false-negatives, in which damage is not identified though it is present. Despite the fact that both these situations are undesirable, the second one can obviously lead to more severe consequences.

\subsection{Damage in Composite Materials}

The use of fibre reinforced plastics $(F R P)$ as an alternative to conventional materials, such as metallic alloys, is suffering an increasing growth, namely in the aeronautical, naval and automotive industries, because of their excellent mechanical properties in conjunction with their low weight and easy shaping. Nevertheless, composite materials are very different from metals with respect to their micromechanical interactions and their particular failure modes, which may be in the form of matrix cracking, fibre breakage, interlaminar delamination or voids (Sanders et al. (1992*), Jacob et al. $\left(1997^{* *}\right)$, Matthews (1999)).

Composite materials possess resistance and tenacity to density relationships many times greater to those of the most common metallic materials, such as steel, aluminum or titanium. However, the extreme sensitivity of composite materials to impact loads constitutes a hindrance to its utilization. In fact, in aeronautical structures, the components have to undergo (i) low energy impacts caused by dropped tools or mishandling during assembly and maintenance, (ii) medium energy impacts caused in-service by foreign objects such as stones or birds and (iii) high energy impacts caused by weaponry projectiles (Matthews (1999), Silva, A. J. P. F. (2001) and Carvalho (2003)).

Typical failure modes in laminated composite materials caused by impacts may be found, for instance, in Carvalho (2003). In a high energy impact, penetration is total and the damaged area is generally small. In a medium energy impact, it is usually possible to visually detect the damage location, which 
is characterized by a local indentation. In a low energy impact (but high enough to produce damage), only a very slight indentation will be seen on the impact surface. This level of damage is often referred to as barely visible impact damage (BVID). Generally, carbon fibre-reinforced plastics (CFRP) are very sensitive to medium and low energy impacts. Matrix cracks will appear and interact, leading to the delamination process. Furthermore, on the opposite side of the impact (subjected to traction loads), it is possible that fibre breakage will occur. This matter has received some attention for damage prediction; for example, Morais et al. (2005) present a study on the influence of laminate thickness on the resistance to repeated low energy impacts of glass, carbon and aramid fabrics reinforced composites, for two levels of impact energy.

Interlaminar delamination highly reduces the component stiffness and buckling load capacity, which in turn influences the structural stability. The influence on the resonant frequencies of the contact forces between delaminated layers, delamination extension and delamination location are studied by Zak et al. (1999**).

Matthews (1999) presents an overview which addresses the nature, consequences and detection of defects in FRP. He distinguishes two groups in the nature of damage: the manufacturing defects and the handling, assembly and in-service damages. The consequences of damage and defects are also addressed, with respect to the composite performance when subjected to compression, tensile, flexural and shear loadings. Finally, some damage detection techniques applied to composite materials are summarized, embracing all the manufacturing and quality control processes.

Although composite materials are receiving a special attention by vibration-based damage detection techniques, other non-destructive techniques are being developed, such as the ESPI (electronic speckle pattern interferometry) or the SQUID (superconducting quantum interference device) (Hiroshi et al. $(2005)$ ).

\subsection{Composite Materials: Damage Effects and Modeling}

Maheri and Adams (2003) use basic laminate plate theory in conjunction with a numerical RayleighRitz method for estimation of the modal damping of anisotropic laminates in free vibration, concluding that a good correlation between the theoretical and experimental results was achieved. Though not explicitly related to damage detection techniques, studies such as these can help researchers in the field of damage detection, since damping may represent an useful feature for damage evaluation in composite materials.

Kisa (2004) investigates the effects of multiple cracks on the dynamic properties of a cantilever $C F R P$ beam. The theoretical model integrates fracture mechanics and substructure coupling, where cracks are modeled as rotational springs. The effects of the location and depth of the cracks, and the volume fraction and orientation of the fibre on the natural frequencies and mode shapes of the beam with transverse cracks, are explored. Kisa (2004) affirms that the followed approach can be used for the analysis of non-linear effects such as interface contact that occurs when the crack closes.

Shu and Della (2004) study the free vibration of beams with multiple enveloping delaminations using an analytical model based on Bernoulli-Euler beam theory. The influence of the delamination dimension and its location on the first two natural frequencies and mode shapes is also discussed.

Ostachowicz and Zak (2004) present some results on damped vibration of a laminated cantilever beam with a single closing delamination. The vibration of the beam is studied in the time domain using a dynamic contact algorithm developed by those authors, based on the Newmark method and incorporating a procedure based on the Newton-Raphson method for solving the equation of motion. They analyze the vibration in the frequency domain. The vibration responses of the beam due to various harmonic and impulse excitations are also considered, with different delamination locations and for different delamination lengths, as well as changes in the damping dissipation energy due to delamination. 
Le Page et al. (2004) develop bi-dimensional (plane strain) finite element (FE) models to analyze matrix cracking development in woven fabric laminates, as a function of the number of reinforcing layers. It is shown that stiffness is relatively insensitive to these geometric variations, though the strain energy release rate related to the crack formation is significantly influenced by its location. Particularly, where the crack formation is associated with local bending, the energy release rate increases with deformation. The inclusion of geometric non-linearities has been shown to affect the results for models which exhibit higher bending deformation. Also, $F E$ models of cross-ply laminates were made to serve both as a comparison and to evaluate whether the behavior of woven fabric laminates can or cannot be described in terms of cross-ply laminates.

Tippetts and Hemez (2005) develop FE models to predict impact damage in composite plates. The failure modes addressed are ply splits (a special combination of matrix cracking and debonding with fibre breakage) and delamination. The plate structural model uses a finite element formulation with a cohesive zone model $(C Z M)$ to simulate the possible fracture surfaces characteristic of impact damage. This model was validated with experimental tests.

Based on the linear fracture mechanics, the Castigliano theorem and classical lamination theory, Wang et al. (2005) investigate the coupled bending and torsional vibration of a fiber-reinforced composite cantilever beam with an edge surface crack. Some important conclusions were drawn. The natural frequency shifts, along with observations on the mode shape changes, may be used to detect both the crack location and its depth for on-line SHM. Also, the presented model and the results may be useful for predicting flutter speed reduction in aircraft with composite wings due to fatigue cracking.

\section{SOME DAMAGE DETECTION TECHNIQUES}

\subsection{Natural Frequencies and $F R F s$}

The development of modal analysis techniques for damage detection and SHM arose from the observation that changes in the structural properties have consequences on the natural frequencies. Nevertheless, the relatively low sensitivity of natural frequency to damage requires high levels of damage and that measurements are made with high accuracy for reliability. Moreover, the capacity for locating damage is somewhat limited, once natural frequencies are global parameters and modes can only be associated to local responses at high frequencies.

Methods based on natural frequency shifts often fall into one of two categories: the forward and the inverse problem. The forward problem consists in determining which will be the natural frequency changes due to a known damage case (which may include its location, extension and type). Typically, damage is modelled numerically and the natural frequencies are measured experimentally and compared to those related to each of the damage cases initially predicted. The inverse problem consists of determining damage parameters, e.g., crack length or its location, from changes in the natural frequencies.

According to Doebling et al. (1996**), Lifshitz and Rotem $\left(1969^{*}\right)$ present what may be the first journal article to propose the use of vibration measurements for damage detection. They search for changes in the dynamic moduli, which can be related to shifts in the natural frequencies, to detect damage in elastomers.

Cawley and Adams (1979*) give a formulation for damage detection, localization and quantification, based on the ratio between frequency shifts for modes $i$ and $j, \Delta \omega_{i} / \Delta \omega_{j}$. Location is determined by minimizing the error between the measured frequency shifts of a couple of modes and those predicted by a local stiffness reduction model. In this formulation, neither multiple damage is taken into account nor damping changes are considered, though the authors agreed that damping might suffer an increase with damage. The results are based on $F E$ models of aluminum and $C F R P$ plates. 
Tracy and Pardoen (1989*) present experimental results of a study on the effects of the length of a midplane delamination in the frequency shifts of the first four modes of orthotropic graphite-epoxy laminate beams. The beam is divided into four sections in the analytical model: above, below, and on either side of the delamination. For midplane centered delamination, it was observed that its presence degraded the even numbered vibration modes more rapidly than the odd numbered vibration modes. Unless the delamination was in a region of the mode shape where the shear forces were high, the natural frequency would not be significantly modified. Thus, in the presence of delamination in areas where the mode shape exhibits high curvatures (second derivative of deflection), little frequency shifts take place. On the contrary, natural frequency variations will have maximum evidence close to an area of higher shear force (related to the third derivative of deflection).

Stubbs and Osegueda (1990a*) (1990b*) develop damage detection methods based on modal changes of specific structural components such as beams, plates and shells. The method relates frequency shifts with changes in member stiffness using a sensitivity relationship. Stiffness reductions can be located solving an inverse problem, since damage is defined as a stiffness reduction of one of the elements forming the structure. It is concluded that it is possible to locate multiple damage, at least in a beam. However, false-positives occurred, though generally within an order of magnitude much lower than the one observed in places where damage was actually present. Moreover, this sensitivity method has difficulties when the number of modes is fewer than the number of the damage parameters.

Sanders et al. $(1992 *)$ use the frequency sensitivity method developed by Stubbs and Osegueda $\left(1990 a^{*}\right)$, combined with an internal-state-variable theory, to detect, locate and quantify damage in CFRP beams. This method includes parameters which indicate two types of damage: matrix micro-cracking by changes in the extensional stiffness, and transverse cracks in the 90 -degree plies by changes in the bending stiffness. Despite the sensitivity equations be only valid for viscous damping, they argued that the damping had little influence in the application of the methodology. Finally, due to the fact that damage was distributed uniformly along the beam length, it was not possible to show the ability of the method to locate damage.

Silva, J. M. M. and Gomes (1990*) perform an extensive experimental dynamic analysis of free-free beams, with slots ranging in depths from $1 / 8$ to $1 / 2$ of the beam thickness, introduced in both dimensions $(x$ and $y$ ) of the cross section and in different locations. Later, Silva, J. M. M. and Gomes (1991) compare both the experimental and theoretical methods, based on the premise that the development of a crack, at a certain location, corresponds to a sudden reduction of the bending stiffness of the beam, at that same location. The crack was modeled as a torsional spring representing the bending stiffness at the crack location.

Using the same grounds, Silva, J. M. M. and Gomes (1994*) suggest a technique for damage detection in beams, based on the estimation of frequency shifts as a function of the crack length and position. An optimization algorithm, developed by Gomes and Silva (1992) and designated as CRACAR, was used to search over combinations of crack lengths and locations. To overcome the differences between the experimental and analytical models, they suggested a simple correction quotient, based on the natural frequencies, which they have shown to be a reliable tool.

Hearn and Testa $\left(1991^{*}\right)$ develop a damage detection method which evaluates the ratio of frequency shifts for various vibration modes. Assuming that the mass does not change as a result of damage, and neglecting second-order terms in the formulation, they showed that the change $\Delta \omega_{i}$ in the $i^{\text {th }}$ natural frequency that results from damage can be related to the matrix of change in element $N$ stiffness $\left[\Delta k_{N}\right]$ and to the element deformation vector $\left\{\varepsilon_{N}(\Phi)\right\}$ evaluated from the mode shape vectors:

$$
\Delta \omega_{i}^{2}=\frac{\left\{\varepsilon_{N}\left(\Phi_{i}\right)\right\}^{T}\left[\Delta k_{N}\right]\left\{\varepsilon_{N}\left(\Phi_{i}\right)\right\}}{\left\{\Phi_{i}\right\}^{T}[M]\left\{\Phi_{i}\right\}}
$$

where $[M]$ is the mass matrix and $\left\{\Phi_{i}\right\}$ is the $i^{\text {th }}$ mass-normalized mode shape vector. Those authors noted that expression (1), which resembles Rayleigh's quotient, seems to support the idea that if an element must develop a high level of potential energy because of the deformations imposed by a 
vibration mode, then damage in that member will have a strong influence on the natural frequency of the mode shape. The converse is also true, and because the natural mode shapes are distinct, the contribution to potential energy made by any one member will be different for each mode. In the case where damage is limited to a stiffness component of the element and if one takes the ratio between the frequency shifts for modes $i$ and $j$, it is possible to show that the effects of the damage will be reduced simply to a function of damage location, $\Delta \omega_{i}^{2} / \Delta \omega_{j}^{2}$, illustrating the characteristic influence of each member on the natural frequencies of the structure. The characteristic influence can be determined from pre-damaged modal properties. Damage is located by selecting the member which characteristic influence is closer to the ratio $\Delta \omega_{i}^{2} / \Delta \omega_{j}^{2}$.

Penny et al. $\left(1993^{*}\right)$ apply a statistical method to identify the most likely damage location, using a generalized least-squares theory. The method uses the ratio of natural frequencies from both the measured and analytical data. The damage case is indicated by the minimal error in this fit.

Messina et al. (1992) propose the damage location assurance criterion (DLAC) in location $j$, which is a correlation similar to the modal assurance criterion (MAC) (Allemang and Brown (1982)), given by:

$$
\operatorname{DLAC}(j)=\frac{\left|\left\{(\Delta \omega)_{X}\right\}^{T}\left\{(\Delta \omega)_{A}\right\}\right|^{2}}{\left(\left\{(\Delta \omega)_{X}\right\}^{T}\left\{(\Delta \omega)_{X}\right\}\right)\left(\left\{(\Delta \omega)_{A}\right\}^{T}\left\{(\Delta \omega)_{A}\right\}^{T}\right)}
$$

where $\left\{(\Delta \omega)_{X}\right\}$ is the experimental frequency shift vector and $\left\{(\Delta \omega)_{A}\right\}$ is the analytical frequency shift vector obtained from an analytical model for a given damage location. A zero value indicates no correlation and a unity value indicates perfect correlation between the vectors involved in the DLAC relationship. Damage location and dimension is identified by maximizing this objective function.

Messina et al. (1996) show that it is possible to better locate damage if the frequency shifts are normalized relative to the undamaged structural frequencies, so that one may weigh the contribution of each vibration mode, since higher frequencies tend to suffer more pronounced shifts.

The multiple damage location assurance criterion (MDLAC), proposed by Messina et al. (1998**), is an extension of the DLAC to multiple damage detection. Using the same principles, the damage state is indicated by search of a damage vector $\{\triangle D\}$ which maximizes the MDLAC. This formulation allows for relative quantification of the damage in each location, but not for an absolute quantification. However, since the experimental frequency shift vector $\left\{(\Delta \omega)_{X}\right\}$ can be known, it is possible to estimate a scalar severity coefficient $C$, in such a way that $C \cdot\{\Delta D\}$ gives the actual damage percentage present. This scaling constant $C$ can be estimated by either a first or second order approach, but these authors note that, although the second order approximation provides better results, for routine monitoring purposes where precise knowledge of the defect size is less important than its location, the first order approximation is likely to be an adequate choice due to its relative simplicity.

Boltezar et al. (1998) locate transverse cracks in flexural vibrations of free-free beams, by following an inverse problem. The method is based on the assumption that the crack stiffness does not depend on the frequency of vibration, i.e., the values of the crack stiffness, which is modelled as a linear torsional spring, must be the same at the crack position for all of the measured natural frequencies. As a result, by plotting the relative stiffness along the length of the beam for distinct natural frequencies (at least two), the crack location can be identified by the intersection of these curves. These authors mentioned that this idea had already been proposed by Adams et al. $\left(1978^{*}\right)$ for axial vibrations, being extended in their article for flexural vibrations in one-dimensional beams, allowing to obtain better results. Since this model is based on the Bernoulli-Euler beam theory, the authors pay special attention to the problem of accurately knowing the values of the material properties, in particular the Young modulus, which can be overcome by calculating its 'effective' value as suggested in Adams et al. (1978*). 
Sampaio et al. (2003) and Sampaio and Maia (2004) propose the detection and relative damage quantification indicator $(D R Q)$, based on the use of the frequency domain assurance criterion $(F D A C)$, as an effective damage indicator, also assessing the distinction of a positive occurrence from a false alarm. The column vector $j$ of the receptance matrix $\left\{\alpha_{j}(\omega)\right\}$ is the operational deflection shape $(O D S)$ which describes the shape (in space) exhibited by the structure at each excitation frequency, $\omega$, given by the responses normalized by the applied forces. When a structure is damaged its stiffness and damping change and, in consequence, so does the receptance matrix $[\alpha(\omega)]$. Thus, it is reasonable to assume that the smaller the degree of correlation between the column vectors (ODSs) of $[\alpha(\omega)]$ and $\left[{ }^{d} \alpha(\omega)\right]$, where the superscript $d$ stands for damaged, the larger is the damage. To measure the degree of correlation between the ODSs, Pascual et al. (1997) proposed the FDAC:

$$
F D A C_{j}\left(\omega_{1}, \omega_{2}\right)=\frac{\left|\sum_{i=1}^{n}{ }^{d} \alpha_{i j}\left(\omega_{2}\right) \alpha_{i j}^{*}\left(\omega_{1}\right)\right|^{2}}{\sum_{i=1}^{n}\left[{ }^{d} \alpha_{i j}\left(\omega_{2}\right)^{d} \alpha_{i j}^{*}\left(\omega_{2}\right)\right] \sum_{i=1}^{n}\left[\alpha_{i j}\left(\omega_{1}\right) \alpha_{i j}^{*}\left(\omega_{1}\right)\right]}
$$

where $n$ is the total number of co-ordinates or measurement points. A simplified form of the FDAC is referred to as the response vector assurance criterion (RVAC) (Heylen et al. (1998)), with only one applied force (so that the receptance matrix turns to be a single vector) and pairs of ODSs at the same frequency $\omega$ :

$$
R V A C(\omega)=\frac{\left|\sum_{i=1}^{n}{ }^{d} \alpha_{i}(\omega) \alpha_{i}^{*}(\omega)\right|^{2}}{\sum_{i=1}^{n}\left[{ }^{d} \alpha_{i}(\omega)^{d} \alpha_{i}^{*}(\omega)\right] \sum_{i=1}^{n}\left[\alpha_{i}(\omega) \alpha_{i}^{*}(\omega)\right]}
$$

From this definition, Sampaio et al. (2003) and Sampaio and Maia (2004) formulate the $D R Q$, which is nothing more than an arithmetic average of the RVACs along the frequency. They also propose a normalization algorithm for the $D R Q$, based on various damage cases, which is referred to as normalization of the maximum occurrences, DRQi. At last, and because some of the best known damage localization methods use the second spatial derivative of the $O D S s$ to locate damage, like the damage index and mode shape curvature (MSC) (Sampaio et al. (1999) e Maia et al. (2003)), one can alternatively calculate the $D R Q^{\prime \prime}$ based on these derivatives and using, for the $O D S s$, a central difference approximation. It was found that the $D R Q$ indicator is able to detect damage, recognizing a true damage state from a false one and it is also able to distinguish adequately different severity damage cases. Nevertheless, it was also found that the versions of the $D R Q$ indicator using the second spatial derivatives of the ODSs did not perform much better that the versions using only the ODSs.

Zang et al. (2003a) present two criteria to correlate measured frequency responses from multiple sensors and proposed to use them as indicators for structural damage detection. The first criterion is the global shape correlation (GSC) function that is sensitive to mode shape differences but not to relative scales, being defined as:

$$
G S C(\omega)=\frac{\left|\left\{H_{x 1}(\omega)\right\}^{H}\left\{H_{x 2}(\omega)\right\}\right|^{2}}{\left(\left\{H_{x 1}(\omega)\right\}^{H}\left\{H_{x 1}(\omega)\right\}\right)\left(\left\{H_{x 2}(\omega)\right\}^{H}\left\{H_{x 2}(\omega)\right\}\right)}
$$

where $\left\{H_{x 1}(\omega)\right\}$ is a column of $F R F$ baseline data measured initially at frequency $\omega$ and $\left\{H_{x 2}(\omega)\right\}$ is a column of the current measured $F R F$ data. This function exists for all frequencies and the sum is 
over all locations. The second criterion, based on actual response amplitudes, is the global amplitude correlation $(G A C)$ :

$$
\operatorname{GAC}(\omega)=\frac{2\left|\left\{H_{x 1}(\omega)\right\}^{H}\left\{H_{x 2}(\omega)\right\}\right|}{\left(\left\{H_{x 1}(\omega)\right\}^{H}\left\{H_{x 1}(\omega)\right\}\right)+\left(\left\{H_{x 2}(\omega)\right\}^{H}\left\{H_{x 2}(\omega)\right\}\right)}
$$

Both correlation criteria given by (5) and (6) are a function of frequency and uniquely map a set of complex responses to a real scalar between zero and unity. These authors argue that a simultaneous use of both correlation criteria should be able to quantify the closeness of two sets of vibration data. The averaged integrations of the GSC and GAC functions along the frequency points over the measurement range are also proposed, referred to as averaged integration GSC (AIGSC) and averaged integration $G A C$ (AIGAC), as damage indicators for SHM. An experimental test on a bookshelf structure was conducted, but it was concluded that further studies would be needed to develop approaches that could accurately assess structural states and damage. An intelligent decision making method based on the radial basis function $(R B F)$ neural network is suggested by Zang et al. (2003b).

\subsection{Mode Shape Changes}

According to Doebling et al. (1996**), West (1984*) presents what is possibly the first systematic use of mode shape information for the location of structural damage without the use of a prior $F E$ model. West $\left(1984^{*}\right)$ uses the MAC to determine the level of correlation between modes from the test of an undamaged Space Shuttle Orbiter body flap and the modes from the test of the flap after it has been exposed to acoustic loading.

Kim, J. H. et al. (1992*) investigate the use of the MAC and some of its forms for locating structural damage. The $M A C$, which is probably the most common way to establish a correlation between experimental and analytical models, is defined as (Allemang and Brown (1982)):

$$
\operatorname{MAC}\left(\left\{\Phi_{X}\right\}_{i},\left\{\Phi_{A}\right\}_{j}\right)=\frac{\left|\left\{\Phi_{X}\right\}_{i}^{T}\left\{\Phi_{A}^{*}\right\}_{j}\right|^{2}}{\left(\left\{\Phi_{X}\right\}_{i}^{T}\left\{\Phi_{X}^{*}\right\}_{i}\right)\left(\left\{\Phi_{A}\right\}_{j}^{T}\left\{\Phi_{A}^{*}\right\}_{j}\right)}
$$

where the $X$ and $A$ subscripts refer to, respectively, experimental and analytical vibration modes. This correlation results in a single scalar number with a value ranging from zero to unity. A unity value means that the mode shapes are identical, whereas a zero value indicates orthogonality between the vectors, i.e., the mode shapes are 'totally different'. Although the $M A C$ can provide a good indication of the disparity between two sets of data, it does not show explicitly where in the structure is the source of discrepancy. The co-ordinate MAC $(C O M A C)$ has been developed from the original MAC. It is the reverse of the $M A C$ in that it measures the correlation at each degree-of-freedom $(D O F)$ averaged over the set of correlated mode pairs. The COMAC identifies the co-ordinates at which two sets of mode shapes do not agree, and is defined as (Lieven and Ewins (1988)):

$$
\operatorname{COMAC}(i)=\frac{\left(\sum_{j=1}^{n_{C M P}}\left|\left(\phi_{A}\right)_{i j}\left(\phi_{X}^{*}\right)_{i j}\right|\right)^{2}}{\sum_{j=1}^{n_{C M P}}\left|\left(\phi_{A}\right)_{i j}\right| \sum_{j=1}^{n_{C M P}}\left|\left(\phi_{X}\right)_{i j}\right|^{2}}
$$

where $n_{C M P}$ is the number of correlated mode shapes. Although the COMAC can be useful as a tool to locate a discrepancy, it does not have a physical basis. It is advisable to use this method in cases where the structure is tested and modelled in a free-free configuration, because grounding of the structure will amplify the effect of anti-nodes away from the region of constraint and dominate the error 
prediction (Maia and Silva (1997a)). On the other hand, although the COMAC is a useful algorithm to detect errors in spatial models, it does not provide a unique solution to localize the source of error in the structure. Another form of the MAC is the partial MAC (PMAC), which correlates parts of modal vectors and easily allows comparing only these selected parts. Kim, J. H. et al. (1992*) propose the combined use of the COMAC and the PMAC concepts, referred to as the Total MAC, so that one can isolate the structural area where damage has occurred.

Parloo et al. (2002b) (2004) compare input-output and output-only damage identification setups for an aluminum beam structure suffering from fatigue induced crack formation. As shown in literature, there are some methods available for the calculation of sensitivity (derivatives) of eigenvalues and eigenvectors. Expressions for the sensitivity of mode shapes to local changes on mass and stiffness can be found, for instance, in Vanhonacker (1980), Maia and Silva (1997a) or Parloo et al. (2003). For example, the sensitivity of $D O F j$ of mode shape $i$ to a local change in stiffness between DOFs $p$ and $q$ can be given by:

$$
\frac{\partial \phi_{j i}}{\partial k_{p q}}=\left(\phi_{p i}-\phi_{q i}\right) \sum_{r=1, r \neq i}^{n} \frac{1}{\lambda_{r}-\lambda_{i}} \frac{\phi_{p r}-\phi_{q r}}{a_{r}} \phi_{j r}
$$

with $\lambda_{r}$ being the system poles and $a_{r}$ the modal scaling factors. An equivalent formulation can be given for a local change in mass. These expressions are exact if all mode shapes of the test structure are taken into account, though a good approximation can be obtained in practice, where only a limited number of modes are available. In practice, the stochastic errors due to the presence of measurement noise, reveal that calculating mass sensitivities can be numerically more stable than the calculation of the sensitivity to stiffness (e.g., because (9) can make the problem ill-conditioned due to subtractive cancellation). If the reference condition of a structure is altered by either a local change in mass or in stiffness, one can write first-order approximations with respect to the damage parameter. However, it is noted that these approximations are only valid for relatively small damage, which poses no problem, since one wants to detect early damage. In the case where frequency sensitivities to a change in a structural parameter are considered, Parloo et al. (2004) use an iterative weighted pseudo-inverse algorithm technique which allows to better locate damage (Guillaume et al. (2002)).

In order to reduce the calculated sensitivity errors, the estimated modal parameters from output-only data should be as accurate as possible. For this purpose, Guillaume et al. (1998) and Guillaume et al. (1999) propose the use of a maximum likelihood estimator $(M L E)$, which is an unbiased estimator since it takes the noise information in the data into account. Instead of using FRFs, the MLE uses spectral density functions.

Vecchio et al. (2002) present an experimental validation of a modal model based approach to structural damage detection, where output-only vibration data is used. However, operational working conditions are not necessarily stationary, and if small deviations are observed in the modal parameters, it is very difficult to decide whether damage is present or not. The approach consists in monitoring the system along the time. The damage detection algorithms reduce time data to covariance data and perform a statistical $\chi^{2}$-test that allows assessing if the recent data fit the reference model. In a previous work, Vecchio and Van der Auweraer (2001) identified the modal parameters based on the stochastic subspace method, but, in order to improve a faster and easier pole extraction and with the aim at achieving more automation in the damage detection process, Vecchio et al. (2002) introduced a new approach based on the MLE. This approach is applied to a reticular structure that was built for several dynamic tests in the context of the EC Brite-Euram SAM project.

Park, N. G. and Park, Y. S. (2003) introduce a damage detection and localization technique based on incomplete experimental models, since, it is not possible in practice either to measure the responses in all DOFs or to have a reference $F E$ model that can represent the real structure in a precise manner, unless one is studying simple structures. However, this method has the disadvantage of requiring heavy experimentation, because one needs to measure all the $F R F s$ of the reference structure for each considered $D O F$. Furthermore, this technique is not effective through the whole frequency range, and solutions are presented for the frequency range choices by error analysis. 
Lazarov and Trendafilova (2004) investigate the influence of damage on the dynamic characteristics of linear elastic plates. This study is based on the plate theory of Kirchoff, and tests were carried out on a square plate. Damage is introduced as thickness changes and as saw cuts perpendicular to the boundary contour of the plate, its influence on the mode shapes and the modal frequencies of the structure being derived and analyzed. It is first concluded that, from both the numerical and experimental models, the natural frequencies of thin plates are not influenced noticeably by damage. The second conclusion is that the mode shapes undergo considerable changes as a result of the presence of damage. Despite the fact that these conclusions seem not to bring remarkable news, they confirm some hypothesis that have been discussed during this work. These authors also propose a mode shape based damage index for damage localization.

Kim, B. S. et al. (2005) use some damage detection criteria, such as the COMAC, the ECOMAC (Enhanced COMAC, which is based on the average difference between the analytical and experimental modal vector components, and first introduced by Hunt (1992)), the ADSM (Absolute Difference of Strain Mode shapes, which is based on the absolute difference of strain mode shapes, proposed by Qin and Zhang (1998)) and a new method based on the absolute difference of the absolute value strain mode shapes. Kim, B. S. et al. (2005) focus on finding differences of these damage detection criteria caused by different geometry and boundary conditions of gusset plates with cracks. Considering crack localization, these authors concluded that the new method generally performed better than the other methods for the studied example, though it loses on physical meaning.

\section{3. $\quad$ Mode Shape and FRFs Curvatures}

As an alternative to damage identification from mode shape changes, mode shape and FRFs curvatures are being consistently used.

Salawu and Williams (1994*) evaluate the performance of some procedures for locating damage using mode shape curvature $(M S C)$ and mode shape changes. The first method estimates the mode shape curvatures using a central difference approximation as proposed by Pandey et al. (1991*):

$$
v_{j r}^{\prime \prime}=\frac{\phi_{(j+1) r}-2 \phi_{j r}+\phi_{(j-1) r}}{h^{2}}
$$

Here, $h$ is the distance between the measurement co-ordinates and $\phi_{j r}$ are the modal displacements for mode shape $r$ at the measurement co-ordinate $j$. Since a local reduction in stiffness results in a local increase in the curvature $v^{\prime \prime}$, it is reasonable to admit that these can be used to detect, locate and quantify damage. The second method studied by Salawu and Williams (1994*) is based on the mode shape relative differences proposed by Fox (1992), in which a graphical comparison of displacement mode shapes is used to indicate damage position. Those authors also use the MAC and COMAC to correlate mode shapes, but although these criteria showed to be sensitive to damage, they did not provide a clear localization of the damage position in a cantilevered beam. The performance of both the $M S C$ and mode shape relative differences methods was not the desired one, since it is necessary to decide which are the most adequate mode shapes to use. Regarding multiple damage, only the MSC method was able to give an indication of simulated multiple damage locations.

In a paper where the applicability of the $M S C$ changes is investigated for damage detection in a prestressed concrete bridge, Wahab and De Roeck (1999) introduce the curvature damage factor $(C D F)$, where the difference in the $M S C$ for all modes can be summarized in one number for each measurement point. This technique was further applied to a real structure: the Z24 bridge which lies between the villages of Koppigen and Utzenstorf and crosses the highway A1 between Bern and Zurich in Switzerland. The $C D F$ is based on the $M S C$ central difference approximation introduced by Pandey et al. (1991*), (expression (10)), and is given by: 


$$
C D F=\frac{1}{N} \sum_{i=1}^{N}\left|v_{i}^{\prime \prime}-v_{i}^{\prime \prime}\right|
$$

where $N$ stands for the total number of modes to be considered, $v_{i}^{\prime \prime}$ is the curvature of the $i^{\text {th }}$ mode shape of the intact structure and $v_{i}^{\prime \prime d}$ is the curvature of the $i^{\text {th }}$ mode shape of the damaged structure. These authors note that a relatively dense measurement grid is required in order to get a good estimation for higher modes curvatures. When more than one fault exists, it is not possible to detect the various damage locations from a single vibration mode, i.e., all modes should be carefully examined in order to locate all the existing flaws.

Ho and Ewins $\left(2000^{* *}\right)$ try to evaluate if the presumption that damage is located at the point where the mode shape change is the greatest is valid with both simulated and experimental data, since the differentiation process enhances the experimental variations inherent to mode shapes. On the whole, they address five methods based on mode shapes and their derivatives: flexibility index $(F I)$, mode shape curvature $(M S C)$, mode shape curvature square $(M S C S)$, mode shape slope $(M S S)$ and mode shape amplitude comparison (MSAC). If more than one mode is defined, it follows that:

$$
\begin{gathered}
F I_{i}=\sum_{j}\left|{ }^{d} \phi_{i j}^{2}-\phi_{i j}^{2}\right| \\
M S C_{i}=\sum_{j}\left|{ }^{d} \phi_{i j}^{\prime \prime}-\phi_{i j}^{\prime \prime}\right| \\
M S C S_{i}=\sum_{j}\left|{ }^{d} \phi_{i j}^{\prime \prime 2}-\phi_{i j}^{\prime \prime 2}\right| \\
M S S_{i}=\sum_{j}\left|{ }^{d} \phi_{i j}^{\prime 2}-\phi_{i j}^{\prime 2}\right| \\
M S_{i}=\sum_{j}\left|{ }^{d} \phi_{i j}-\phi_{i j}\right|
\end{gathered}
$$

The last two methods, corresponding to expressions (15) and (16), are presented by Ho and Ewins $\left(2000^{* *}\right)$. The first (15) corresponds to an attempt to introduce the mode shape deflection as a sensitive feature to damage while relatively insensitive to experimental variation. The second equation (16) has the advantage of not requiring the mode shape differentiation. In calculating the derivatives of mode shapes, instead of using finite difference approximation, polynomial functions are used: a local polynomial is fit through every four consecutive measurement points and the resulting polynomial is differentiated. These authors conclude that the experimental results show that higher derivatives are more promising for damage identification, but that false damage indications may be observed at mode shape nodal points or where the measurements quality is relatively poor. It was also observed that this may also occur at the boundaries.

Battipede et al. (2001) extend the gapped-smoothing technique to bi-dimensional models or plate-like structures, being shown that the method is able to locate single and multiple damage of medium and great extent. This technique, which had already been applied to one-dimensional models by Ratcliffe and Bagaria (1998) and Ratcliffe (2000), takes advantage on the presence of an irregularity in the curvature shape in order to detect damage. The displacement shape is converted into curvatures by applying a second order finite differentiation procedure:

$$
C_{x x}\left(x_{i}, y_{j}\right)=\frac{Y\left(x_{i+1}, y_{j}\right)-2 Y\left(x_{i}, y_{j}\right)+Y\left(x_{i-1}, y_{j}\right)}{h_{x}^{2}}
$$

in which $Y\left(x_{i}, y_{j}\right)$ is the measured displacement (perpendicular to the plate plane) and $h_{x}$ is the uniform spatial separation of the measurement sensor grid along the $x$ direction. The curvature along 
the $y$ direction, $C_{y y}$, is evaluated similarly. In the absence of damage and other irregularities, the curvature has a smooth shape and can thus be represented as a polynomial function. As a consequence, it may happen that the smooth function and the measured curvature are different when evaluated at the same location, $\left(x_{i}, y_{j}\right)$, which can be an indicator of damage at that location. Besides, the fact that one is dealing with a bi-dimensional model allows taking into account the cross curvature, $C_{x y}$, so that a damage index can be formulated as:

$$
\begin{aligned}
\delta_{i, j}= & a_{x x}\left(C_{x x}^{(m)}\left(x_{i}, y_{j}\right)-C_{x x}\left(x_{i}, y_{j}\right)\right)^{2}+a_{y y}\left(C_{y y}^{(m)}\left(x_{i}, y_{j}\right)-C_{y y}\left(x_{i}, y_{j}\right)\right)^{2} \\
& +a_{x y}\left(C_{x y}^{(m)}\left(x_{i}, y_{j}\right)-C_{x y}\left(x_{i}, y_{j}\right)\right)^{2}
\end{aligned}
$$

where the $a_{i j}$ coefficients can be set to 0 or 1 , to either consider or neglect the corresponding curvature. However, Battipede et al. (2001) considered $a_{x y}=0$ since it is difficult to estimate $C_{x y}$ from experimental data. For an undamaged structure, the difference between measured and fitted data is mainly due to measurement noise, so that in an experimental case the damage index $\delta_{i j}$ is irregular without any sharp peak. Conversely, if the structure is faulty, some peaks will clearly appear in correspondence to the sensors located around the damaged region of the model under consideration. The major advantages of this technique, when applied to a plane rectangular homogeneous plate, are (i) the possibility of locating multiple damage without knowledge of a reference model of the structure and (ii) only a single test is needed to perform on the structure in its current state without knowledge of its history. However, in practice, measured data tend to be polluted by noise, detrimentally affecting the effectiveness of the technique.

Yoon et al. (2005) propose the generalization of the one-dimensional gapped smoothing technique to bi-dimensional models. As before, it is shown that it is possible to locate damage using only data from the damaged structure, i.e., without resorting to a reference model. Provided that it is known that the structure, in its undamaged state, is homogeneous with respect to stiffness, the procedure will detect the non-homogeneous areas that are caused by damage. Variability indices are generated for each test point on the structure, which statistical treatment and outlier detection enables discrimination of areas with significant stiffness variability. The structural irregularity index is calculated as:

$$
\delta_{i, j}=\left|\nabla^{2} \psi_{i, j}-C_{i, j}\right|
$$

where $\nabla^{2} \psi_{i, j}$ is the curvature of either a mode shape or an $O D S$ and $C_{i, j}$ is the smoothed curvature shape. It has been shown that this method allows for the detection of size and location of relatively small localized stiffness reductions in homogeneous plate-like structures. Analytical models or reference experimental models of the structure in the undamaged state are not needed. Also, the results using the broadband $O D S$ data showed superior performances over those using the mode shapes. However, in the case of large areas or uniform damage (when compared to the spacing and number of measurement points), the algorithm identified the edges of the damage, which can make the interpretation of results more difficult. It was concluded that further research is required in order to establish a quantitative relationship between the local stiffness reductions and the irregularity indices.

Maia et al. (2003) present a series of numerical simulations as well as an experimental example on a simple beam in order to compare various damage detection methods based on mode shape changes. It is also proposed a generalization of these methods to the whole frequency ranges of measurement, i.e., methods based on mode shapes become based on $O D S s$. This way, one may avoid modal identification which can be a time consuming process and can filter relevant information. The studied methods are within two major groups: mode shape damage detection methods and $F R F$-based damage detection methods. In the first group, they include all the methods overviewed by Ho and Ewins $\left(2000^{* *}\right)$, except the flexibility index $(F I)$ method. They also include the damage index method, developed by 
Stubbs et al. $\left(1995^{*}\right)$, which is based on the modal strain energy decrease between two structural DOFs for linear-elastic Bernoulli-Euler beams, and given by:

$$
\beta_{i j}=\frac{\left(\int_{a}^{b}\left[{ }^{d} \phi_{j}{ }^{\prime \prime}(x)\right]^{2} d x+\int_{0}^{L}\left[{ }^{d} \phi_{j}{ }^{\prime \prime}(x)\right]^{2} d x\right) \int_{0}^{L}\left[\phi_{j}{ }^{\prime \prime}(x)\right]^{2} d x}{\left(\int_{a}^{b}\left[\phi_{j}{ }^{\prime \prime}(x)\right]^{2} d x+\int_{0}^{L}\left[\phi_{j}{ }^{\prime \prime}(x)\right]^{2} d x\right) \int_{0}^{L}\left[{ }^{d} \phi_{j}{ }^{\prime \prime}(x)\right]^{2} d x}
$$

where $a$ and $b$ are the limits of a segment $i$ of the beam where damage is being evaluated and $L$ is the total length of the beam. For the purpose of the article presented by Maia et al. (2003), the discrete formulation of expression (20) is used. For more than one mode, the damage index can be defined as:

$$
D I_{i}=\sum_{j} \beta_{i j}
$$

Cornwell et al. (1997) generalize the damage index method to plate-like structures that are characterized by a two-dimensional curvature. One of the advantages of this strain-energy based method is that it does not require a well correlated $F E$ model and/or mass normalized mode shapes. The mode shape detection methods group is based on the presumption that damage is located between DOFs where the change of a mode shape function is the greatest. The second group distinguished by Maia et al. (2003), the $F R F$-based damage detection methods, includes the $F R F$-based mode shape, the $F R F$-based mode shape slope, the $F R F$-based mode shape curvature (also presented by Sampaio et al. (1999)), the $F R F$-based mode shape curvature square and the $F R F$-based damage index. All these methods are equivalent to the mode shape detection methods, with the difference that they use FRFs instead of mode shapes. In Maia et al. (1997b) it is noted that when calculating the damage indices for the $F R F$-based methods, as we go along the frequency range, adding more and more information, the results begin to degenerate instead of improving. To overcome this, for each frequency, the location where the difference of damage and undamaged case is a maximum is looked up and, at that location, an occurrence is counted. The occurrences are summed up along the frequency range for each location, and damage is detected in the location where the greatest number of occurrences has been counted. Maia et al. (2003) found that the methods based on the curvatures performed better. However, the false damage indications are a problem that needs close attention. Those authors suggest that some improvements could be made in the interpolation process, in defining a noise level under which the results are not considered, in the method to calculate the maximum occurrences, in applying statistics to the results, and finally, in the set-up and skill of the experimentalist.

Sampaio et al. (1999) compare the FRF curvature method, which encompasses the first three levels of the damage identification process (existence, location and extent), with two of the most referenced methods in literature: the mode shape curvature (MSC) method and the damage index method. The $F R F$ curvature method is based only on the measured data without need for any modal identification, and it is an extension of the Pandey et al. (1991*) method to all frequencies in the measurement range and not just the modal frequencies, i.e., it uses $F R F$ data rather than just mode shape data. In fact, the method uses something like an 'operational mode shape' defined, for each frequency, by the frequency response at different locations along the structure. The absolute difference between the $F R F$ curvatures of the damaged and undamaged structure at location $i$, along the chosen frequency range $\omega$, is calculated, for an applied force at point $j$, by:

$$
\Delta \alpha_{i j}{ }^{\prime \prime}=\sum_{\omega}\left|{ }^{d} \alpha_{i j}{ }^{\prime \prime}(\omega)-\alpha_{i j}{ }^{\prime \prime}(\omega)\right|
$$

Finally, one can sum up for several force location cases. This technique was tested using experimental data gathered from the I-40 bridge over the Rio Grande in Albuquerque, New Mexico, USA, following previous work done by Jauregui and Farrar (1986a*) (1986b*) of the Los Alamos National Laboratory (LANL) in the USA. As main conclusions on the FRF curvature method, Sampaio et al. (1999) point out the following: (i) the method worked better for a range before the first anti-resonance or resonance (whichever comes first), since for wider frequency ranges, including several modes, the difference of curvatures of the damaged and undamaged model becomes less significant when compared with the 
amplitude difference arising from the resonances' frequency shift, because of the loss of stiffness; (ii) the influence of the position of the exciting force seemed not to be important, according to the numerical model; (iii) the method is quite insensitive to noise; (iv) it was possible to detect, locate and quantify damage, though this last aspect deserves further developments; (v) the method has the great advantage of being simple and not being necessary to perform modal identification. With respect to the comparison established between the three methods, Sampaio et al. (1999) argue that the FRF curvature method had the best performance, although, e.g., the $M S C$ method produces better results for higher order modes.

Pirner and Urushadze (2004) compare the CAMOSUC (change of mode surface curvature) with earlier methods to detect the magnitude and location of damage based on, namely, the MAC, COMAC, and the error-matrix. The CAMOSUC is defined as the difference of the mode shape curvatures between the undamaged and damaged states. Thus, each term in the curvature damage factor $(C D F)$ sum (11) is the CAMOSUC itself. These authors present detailed applications of some of these methods to real cases, such as a Plexiglas square plate, a Plexiglas model of a railroad bridge section, a three-span prestressed concrete bridge, floor slabs of a department store and an hyperbolic cooling tower.

Hamey et al. (2004) approach experimental aspects of methods which make use of mode shape curvatures. They consider four methods to establish a comparison between them: the absolute difference of curvature mode shape method, the $C D F$ method, the damage index method and the $F R F$ curvature method. However, instead of obtaining approximations to the second derivatives of the displacements, as usual, it is proposed to use the direct measurements of the curvatures of the mode shapes obtained from piezoelectric materials. They used piezoceramic patches for sweep-sine continuous excitation and a hammer for impulse excitation. Sixteen polymeric PVDF sensors were distributed along the beam length, on one face of the beam. Also, they tested several cases of damage: a transverse crack, three scenarios of controlled non-symmetric delamination and impact damage. They point out that, in general, the impulse excitation produced slightly better results than the continuous excitation. With respect to the identification methods, they observed that the damage index method performed better than the others both on damage detection and localization. According to these authors, the FRF curvature method turned out to be the one which has produced the worst results. Also, they observed that when the sensors are placed on the opposite side of the delamination, for the cases where delamination had greater dimensions, it was possible to obtain better results, though sensor position seemed not to bring out better results for the other damage cases.

Kim, B. H. et al. (2005) try to extend the $M S C$ and damage index methods by resolving some deficiencies of these methods. They solve a set of linear algebraic equations referred to as flexural damage index equations (FDIE), which allow avoiding the singularity problem near the inflexion points and the mode selection problem of the MSC and damage index methods. The FDIE shows that the damage and the curvature of flexibility have a strong relationship. Also, this method is able to detect, locate and size structural damage in a plate-like structure using the measured modal parameters. However, a fine sensor interval is required if one wants to get an accurate estimate of the severity of damage.

Zhu and Xu (2005) present a sensitivity-based method for localization and assessment of damage in mono-coupled periodic structures, in which slopes and curvatures of mode shapes are used to localize damage, and natural frequencies are then used to quantify its extent. The expressions of sensitivity coefficients of mode shapes, slopes and curvatures of a mono-coupled periodic system are first derived in terms of receptances of a periodic element. The numerical and experimental examples show that curvatures of modal shapes are the most sensitive to damage, but slopes of mode shapes seem to provide a better indication of the damage location. Also, the larger changes in the natural frequencies imply higher sensitivity of these modes to damage, which is useful for choosing a few of the lower frequency modes to localize damage. The method allows for multiple damage detection and localization, with different simultaneous extents, using a few of the slopes and curvatures of the lower order mode shapes, though the accuracy for quantifying the damage size highly depends on the number of used frequencies. 


\subsection{ARMA Family Models}

Brincker et al. (1995a*) use a statistical analysis based on the natural frequency shifts to detect damage in two concrete beams with different reinforcement ratios. The modal parameters (natural frequencies and modal dampings) are estimated from the response time series (accelerations) using the so called auto-regressive moving average (ARMA), identical to the one used by Brincker et al. (1995b*) in an offshore platform. Referring to Davies and Hammond (1984), Pandit and Metha (1985) and Safak (1991), Brincker et al. (1995a*) mention that the ARMA models have been developed mainly for application in economics and electrical engineering, but since they are considered to be a more effective way of estimating modal parameter than Fast Fourier Transform $(F F T)$ based techniques, their use on structural systems has been increasing during recent years. A more complete version is the ARMA with exogenous input (ARMAX). The $[n, m]$ order ARMAX model that describes the time response $y(t)$ as a linear combination of the last $n$ responses as well as the last $m$ unknown inputs and $p$ known inputs is given by:

$$
y(t)=\sum_{i=1}^{n} c(i) y(t-i)+\sum_{i=1}^{p} b(i) x(t-i)-\sum_{i=1}^{m} d(i) e(t-i)+e(t)
$$

where $c(i)$ is the auto-regressive parameter describing the response $y(t)$ as a linear regression of the last $n$ values and $d(i)$ and $b(i)$ are the moving average parameters which describe the response $y(t)$ as a linear regression of the last values of, respectively, an unknown input time series, $e(t)$, which may be assumed as white noise, and a known time series, $x(t)$. The $c(i)(A R), d(i)(M A)$ and $b(i)$ (X) parameters are determined by minimizing the variance of the noise time series $e(t)$, i.e., based on the measured response and on the predicted response given by (23). When the $A R$ parameters are estimated, the roots of the characteristic polynomial equation that contains these parameters can be related to the natural frequencies and to the modal dampings. Hence, the ARMAX can be utilized to examine these parameters variations along the time. Also, Brincker et al. (1995a*) define a statistical significance indicator which accounts for the changes in the natural frequencies, so that they can give a quantifiable estimate of the structural modifications. It was shown that the significance indicators are sensitive to structural damage, but they are not able to provide an accurate estimate of damage location. Finally, it was observed that, for the studied beams, the differences between the ARMA and $A R M A X$ were quite small. Thus, it was concluded that knowing the input signal is not essential for the detection of damage in the studied beams.

Wei et al. (2005) use nonlinear ARMA with exogenous input (NARMAX) models to assess internal delamination in multi-layer composite plates. These authors state that the relationship between input and output is nonlinear for multi-layer composite panels. According to them, the NARMAX model was proposed by Leontaritis and Billings (1985a) (1985b) as a general parametric form for modeling nonlinear systems. NARMAX models describe the nonlinear systems in terms of difference equations relating the current output to combinations of inputs and past outputs. The structure of the proposed model is used to estimate model parameters for damaged vibration systems, and internal delamination is detected by comparing the model parameters between intact and damaged systems. The results show that, for the studied case, NARMAX models allow investigating the behavior of composite models as well as assessing damage in composites, especially if it is in the form of a delamination.

$\mathrm{Lu}$ and Gao (2005) propose an approach which is formulated in the form of a predictive auto-regressive model with exogenous input $(A R X)$, based on the linear dynamic system theory. After some simplifications, the model is expressed in such a way that only response signals are involved, with a response at one location chosen as the 'input' of the model. The residual error of the established model when applied on actually measured signals reflects the structural change, and the standard deviation of the residual error is found to be a damage sensitive feature. It was observed that the proposed $A R X$ model can have undesired behaviors when the location of the chosen 'input' response is 
near the location of the damage. For this reason, they recommend that in a diagnosis situation two separate runs of the procedure are carried out using two different 'input' locations. It was also noted that the standard deviation of the residual error of the $A R X$ model, although sensitive to the presence of damage, does not give a precise indication of the degree of damage, so further research is required.

In an earlier work, Sohn and Farrar (2001b) had presented a two iteration AR-ARX model in order to predict the time series and subsequently use the standard deviation ratio of the residual errors as the damage sensitivity feature. The residual error is the difference between the actual measurements and the predicted responses from the combination of both the $A R$ and $A R X$ models.

\subsection{Dynamic Flexibility}

Another class of damage detection methods is based on the use of the dynamic flexibility matrix to estimate changes in the static behavior of the structure. The dynamic flexibility matrix is a transfer function, defined as the inverse of the static stiffness matrix. Thus, each column of the flexibility matrix represents the displacement pattern of the structure associated with a unit force applied at the associated DOF. Damage is then identified by comparison of both the flexibility matrices of the structure in the undamaged (or obtained from a $F E$ model) and damaged states. Due to the inverse relation to the square of the modal frequencies, the dynamic flexibility matrix is very sensitive to changes in the lower order modes, whereas the stiffness matrix is more sensitive to higher order modes. Based on this, Doebling et al. (1996**) distinguished five different approaches: comparison of flexibility changes, unity check method, stiffness error matrix method, effects of residual flexibility and changes in measured stiffness matrix.

Park, Y. S. et al. (1988*) suggest the use of the weighted error-matrix method, comparing it to the error-matrix method (Sidhu and Ewins (1984) and He and Ewins (1985*)). The stiffness error matrix can provide valuable information on the position of the damaged area, being defined as:

$$
[E]=\left[K_{2}\right]-\left[K_{1}\right]
$$

where $\left[K_{2}\right]$ and $\left[K_{1}\right]$ are the stiffness matrices of the evaluated members in the damaged and undamaged states, respectively. Although $\left[K_{1}\right]$ can be estimated from a $F E$ model, it is possible to determine $[E]$ based on experimental data only. When the stiffness error matrix $[E]$ is plotted, the highest peak will indicate the most probable damage location. Due to measurement noise, this method is only reliable when the measured natural frequency shifts and the modal vector changes exceed the magnitude of the measurement errors. Therefore, Park, Y. S. et al. $\left(1988^{*}\right)$ propose the weighted error-matrix method, which magnifies the amount of stiffness error only in certain nodal points related to the damaged element. Although it has been shown that the weighted error-matrix method is more sensitive to damage, since it was possible to accurately detect the structural damaged member even for reduced levels of damage, its complexity does not make it an attractive method. In order to reduce the amount of computations and experiments, it is suggested an iterative 'step-by-step' method, in which the number of elements chosen is being refined in each step.

\subsection{Modal Strain Energy}

Choi and Stubbs (2004) developed a method to locate and size damage in a structure measuring timedomain responses in a set of measurement points. The mean strain energy for a specified time interval is obtained for each element of the structure, being in turn used to build a damage index that represents the ratio of the stiffness parameter of the pre-damaged to the post-damaged structure: 


$$
\beta_{j}=\frac{\sum_{i=1}^{N T}\left\{V_{i}\right\}^{T}[K]\left\{V_{i}\right\}}{\sum_{i=1}^{N T}\left\{V_{i}^{d}\right\}^{T}[K]\left\{V_{i}^{d}\right\}}\left(\frac{\sum_{i=1}^{N T}\left\{V_{i}^{d}\right\}^{T}\left[C_{j}\right]\left\{V_{i}^{d}\right\}+\sum_{i=1}^{N T}\left\{V_{i}^{d}\right\}^{T}[K]\left\{V_{i}^{d}\right\}}{\sum_{i=1}^{N T}\left\{V_{i}\right\}^{T}\left[C_{j}\right]\left\{V_{i}\right\}+\sum_{i=1}^{N T}\left\{V_{i}\right\}^{T}[K]\left\{V_{i}\right\}}\right)
$$

In this expression, $\beta_{j}$ is the damage index for the element $j, N T$ is the number of sampling points, $\left\{V_{i}\right\}$ is the displacement configuration vector at time $t_{i}$, and $\left[C_{j}\right]$ is the geometric portion of the contribution of the $j^{\text {th }}$ element to the system stiffness matrix $[K]$. Possible locations of damage in a structure can be identified by utilizing a classification algorithm with the damage index given by (25) taken as the feature vector. A statistical decision technique of hypothesis testing is used in the classification algorithm, in which the damage indices given by (25) are normalized, assuming that the damage index is a random variable and the collection of the damage indices are distributed normally. Once the possible locations of damage are isolated, corresponding damage severities can be obtained (i.e., the fractional loss in stiffness). These authors present as major conclusions, that the time-domain response may be used directly to localize and size damage in a structure and that it is possible to reduce false-negatives using a lowered significance level for damage localization, with the expense of increasing the number of false-positives. Thereby, the balance among them can represent a measure of the sensitivity of the method as well as of the quality of the results and the effectiveness of the algorithm for damage localization.

Patil and Maiti (2005) provide an experimental verification of an energetic method for prediction of location and size of multiple cracks based on the measurement of natural frequencies for slender cantilevered beams with two and three normal edge cracks. In the theoretical model the beam was divided into a number of segments and each segment was considered to be associated to a damage index. The cracks are represented as torsional springs. The damage index behaves as an indicator of extent of the strain energy stored in the crack, or torsional spring. The method is based on the concept that the strain energy $U$ of a beam containing a crack reduces because the beam can deform easily to the same extent as the uncracked beam. This reduction is equal to the extent of energy stored in the fictious torsional spring (or crack), which, for the case where $m$ cracks are present is:

$$
U=U_{n}-\sum_{i=1}^{m} \frac{M_{i}^{2}}{2 K_{i}}
$$

where $U_{n}$ is the stored energy in the corresponding uncracked beam for vibration mode $n$ and $M_{i}$ and $K_{i}$ are the bending moment at the crack location $x=l_{i}$ and stiffness associated to the crack, respectively. Based on these principles and after several considerations, simplifications and some mathematical manipulation, an expression for the location of a crack in a segment of the beam is suggested. It is concluded that, on the whole, the accuracy of the method is good for the prediction of the crack location, though it is lower for the prediction of the crack size. Accuracy reduces as the number of cracks increases. One of the major drawbacks of this method is revealed when it is observed that a number of measured frequencies equal to twice the number of cracks is the adequate quantity for the prediction of location and size of all cracks, which in a practical sense may not be possible to determine in advance.

\subsection{Transmissibility}

Sampaio et al. (2000) show that a minor stiffness change can result in a noticeable change of transmissibility relating responses at points around damage. Considering a general structure with $i$ measuring co-ordinates and $j$ excitation co-ordinates, it is possible to compute the transmissibility 
matrix for either the reference (or undamaged) and damaged states. The transmissibility matrices are square, with $m \times m$ elements and a zero diagonal. With this arrangement, it is possible to write:

$$
\{x\}=[T]\{x\}
$$

This is a special case of the transmissibility matrix, which relates the set of $m$ responses with itself. The sum of all the transmissibility matrices in the frequency range of interest allows obtaining a unique matrix for each case, $\left[{ }^{d} S T\right]$ for the damaged and $[S T]$ for the undamaged case. Their difference $[\Delta S T]=\left[{ }^{d} S T\right]-[S T]$ will show the location of damage, since its values should present a significant increase near the damaged region. To enhance the location, the different values at each line $i$ of the $[\Delta S T]$ matrix are summed and the second derivative $\Delta S T_{i}^{\prime \prime}$ is calculated by a central difference approximation. Matrices $\left[{ }^{d} S T\right]$ e $[S T]$ can be represented in a contour plot, where the rows are the $x$-axis and the columns are the $y$-axis. Any noticeable change of these plots may mean damage existence. To locate it, one can observe the bar plot of $\Delta S T_{i}^{\prime \prime}$. Basically, damage will be located between the co-ordinates that show major amplitudes. Sampaio et al. (2000) show another way of applying the transmissibility concept to damage detection, referred as the pseudo-transmissibility matrix method, which uses $F R F s$ instead of responses only. Despite the fact that this version had a better performance, these authors note that the former (the one using the transmissibility matrix) is more consistent (or real) because the pattern change is correlated among the various plots. These authors have also developed the frequency of maximum differences algorithm, to improve the accuracy of the transmissibility method and others, such as the FRF curvature method, that uses raw data directly from the FRFs. The transmissibility matrix, pseudo-transmissibility matrix and FRF curvature methods were applied on a 10-DOF numerical model. It was concluded that the frequency of maximum differences greatly improves the methods which use FRFs in damage detection and location. However, the version which uses the transmissibility matrix for several simultaneous forces did not work in the used examples.

Mares et al. (1999**) apply genetic algorithms for assessing damage where the objective function is based on the measured transmissibilities. The method is tested in a numerical model of a four story steel frame structure. The model was developed by having in mind a great in-plane rigidity of the floors with respect to the out-of-plane rigidity of the columns. Four damage scenarios were considered, by combinations of Young modulus reductions and removal of columns and braces. These authors observe that not all the transmissibilities are sensitive to damage in the same way. Therefore, they performed a two-step procedure to select the 'best' transmissibility functions before running the genetic search, in order to enhance the optimization process and hence the damage assessment procedure. The used procedure enabled transmissibility functions to be ranked in terms of the most sensitive to damage. The transmissibilities found to be the most sensitive to damage were used in the formulation of the cost function. The optimization process follows two iterations to obtain the global minimum of the cost function. First, a genetic search is applied on the cost function, and then a classical gradient-based algorithm is run to refine the solution, so that global minima are correctly distinguished from local minima. Mares et al. (1999**) observe that, according to the performed numerical simulations, the use of transmissibility functions provide estimates of the state-of-damage that are sufficiently accurate. However, for the used steel frame structure model, damage in braces was easier to identify than damage in columns.

Johnson, T. J. et al. (2004) present a work on smart sensor arrays with the goal of implementing local vibration-based diagnostic algorithms inside a smart 'black box' to demonstrate the feasibility of distributed health monitoring for damage detection, location and quantification. It was shown that the transmissibility is a good indicator feature of structural damage in spite of environmental fluctuations and boundary conditions non-linearities. For this late reason, the transmissibility-based damage identification technique is referred to as the structural diagnostics using non-linear analysis ( $S D N A)$ approach. This approach is presented, and it is shown that it reduces the number of false diagnoses due 
to non-linearities. Experiments were carried out on two large distributed structures, a building and a rotorcraft fuselage.

\subsection{Damping}

Based on the observation that modal damping is a parameter with higher sensitivity to internal delamination on CFRPs than the natural frequencies, Keye et al. (2001) develop a method which is capable of relating modal damping deviations caused by structural damage to the damage location on the structure. They call the attention to two important aspects on the experimentation. First, when only a single or a small number of sensors is available, the experimental data provides no spatial information on the dynamic response, i.e., on the mode shapes, and the process of localizing structural damage has to cope with eigenfrequencies and modal damping values, which can be extracted from the measured $F R F s$. In such a case, a $F E$ model should be used to locate the damage. Second, since in practice the damage location is unknown, a whole set of damage locations have to be simulated in the numerical model and the modal data must be computed for each damage case. After testing the method on a CFRP plate-like structure, they propose some improvements on the method: (i) to enhance the correlation between numerical and experimental data, updating techniques should be used; (ii) implementation of a systematic mode selection strategy and the weighting of individual modes based on their sensitivities for damage localization; (iii) optimization of the actuator/sensor placement and evaluation of their influence on the damage identification capability; (iv) evaluation of other aspects, such as temperature effects and influence of the excitation method.

Kyriazoglou et al. (2004) explore the use of the specific damping capacity (SDC) for damage detection and localization in composite laminates. One important observation is that the resonant frequency allowed detecting cracks in glass fibre-reinforced laminates while for carbon fibre-reinforced laminates no detectable changes in the resonant frequencies could be found. However, high changes were found in the $S D C$. The method consists of measurements and analysis of the $S D C$ of composite beams vibrated in free-free flexure in their first mode. The $S D C$ is defined as:

$$
S D C=\frac{\Delta U}{U}
$$

where $\Delta U$ is the dissipated energy in one cycle and $U$ is the total energy stored in that cycle. The energy stored by the beam in bending, $U$, is calculated from the mode shape maximum deflection at the center of the beam. The dissipated energy in one cycle is equated to the energy input. Tests have been carried out both in air and in vacuum, being found that air damping significantly affect the measurements, particularly when the beam has off-axis reinforcement.

Yam et al. (2004) proposed to develop a practical method for the location and prediction of damage in CFRPs plates by means of a combination of the measured modal damping and the computed strain energy distribution. First, a $F E$ model is established to estimate the modal parameters, such as natural frequencies, mode shapes and modal strain energy. Based on the numerical model and on the fact that delamination at different regions produce characteristic increases on the modal damping, they are able to experimentally locate damage. These authors note that the numerical simulations provide a good explanation for damping increase due to delamination, i.e., the energy dissipation is mostly induced by the interfacial slip across the delamination and the tendency of penetration between the upper and lower surfaces in the delamination region.

Various authors have tried to study the damping mechanisms in composite materials. For example, Nayfeh (2004) develops a model for vibration parallel to the plane of lamination of a symmetric fivelayer elasto-viscoelastic sandwich beam, since it is known that a sandwich beam consisting of alternating elastic and viscoelastic layers can be designed to exhibit large damping on flexural vibration in the direction normal to the plane of lamination. Also, Berthelot and Sefrani (2004) experimentally analyzed damping of unidirectional glass and Kevlar composites, comparing them to the models of Adams-Bacon, Ni-Adams and complex stiffness. The purpose was to develop an 
analysis of the effect of the fibre-reinforcement orientation in the case of unidirectional layers, since it is known that, at the constituent level, the energy dissipation in fibre-reinforced composites is induced by different mechanisms such as the viscoelastic nature of the matrix and fibre materials, the damping at the fibre-matrix interface, the damping due to damage, etc.

\subsection{Impedance-Based Methods}

Park, G. et al. (2003) present an overview of piezoelectric impedance-based health monitoring where the hardware and software issues are summarized, including a discussion on future research areas and path forward.

Park, G. et al. (1999**) introduce an impedance-based method which uses a piezoelectric transducer (PZT) both as actuator and sensor. It can be shown that the electrical impedance of the PZT is directly related to the structure mechanical impedance (Liang et al. (1994)). Thus, a relationship can be found to determine the structural properties, namely, the mass, stiffness and damping. Any change in the mechanical impedance, which could be caused by the presence of damage, will show up in the electrical impedance of the PZT. The damage state is identified when a defined metric, given by the sum of the squared differences of the impedance between the current and the reference state, becomes larger than a predefined threshold. As advantages, these authors point out that this technique does not require numerical models and that the high-frequency excitation nature makes this technique very sensitive to local structural modifications.

Grisso et al. (2004) use an impedance-based SHM system to detect the onset of transverse matrix cracking in cross-ply graphite/epoxy composite. Ceramic PZT patches are attached to the composite samples (in this case, beams) to simultaneously excite the structure with high-frequency excitations (two frequency ranges, from 10 to $20 \mathrm{kHz}$ and from 40 to $60 \mathrm{kHz}$ ) and monitor any changes in structural mechanical impedance. In order to detect damage severity, these authors use the root mean square deviation $(R M S D)$, where the squared differences of the impedance between the undamaged and actual states are related. These authors conclude that acoustic emissions testing showed a good correlation only for thicker specimens, while the impedance-based method has given better correlation for thinner specimens.

Moura Jr. and Steffen Jr. (2004) try to identify the best frequency bands for impedance-based structural damage identification on flexible structures. Damage is simulated in a cantilevered aluminum beam by adding a mass to the free end of the beam. By observing the results, these authors agreed that, at least for the following setups, the best low frequency value is $15 \mathrm{kHz}$, while the best bandwidth value corresponds to the intermediate one $(4 \mathrm{kHz})$.

Peairs et al. (2005) developed a new modeling technique for impedance-based SHM, combining the spectral element method (SEM) with the electric circuit analysis. These authors argue that $S E M$ has several advantages over other conventional $F E$ techniques, for instance, because $S E M$ models more accurately higher frequency vibrations since the mass is modeled 'exactly' and incorporates higher order models more easily. Sensor multiplexing for transfer impedance and high frequency modeling were also investigated. However, modeling at higher frequencies is more complex because of the presence of the PZT resonances.

Simmers Jr. et al. (2005) apply an impedance-based method to detect and quantify the onset and growth of pre-crack surface corrosion. Three metrics were used: one similar to the one used by Park, G. et al. $\left(1999^{* *}\right)$, the $R M S D$ and a cross-correlation. The experimental results on an aluminum beam indicate that the impedance-based is an effective corrosion detection and tracking method, and that there is a relationship between the metrics and corrosion location, surface coverage and pit depth.

Park, G. et al. (2005) propose to use statistical pattern recognition methods to address damage classification and data mining issues associated to large numbers of impedance signals for health monitoring applications. In order to diagnose damage with statistical confidence, the impedance-based monitoring is cast in the context of an outlier detection framework. The developed statistical process 
control consists of a two-stage prediction model that is a combination of $A R$ and $A R X$ models, the $A R$ $A R X$. The damage-sensitive feature is then computed by differentiating the measured impedance and the output of the $A R X$ model. Because of the non-Gaussian nature of the extracted features, extreme value statistics $(E V S)$ is employed to develop a robust damage classifier. The proposed technique is tested in a numerical example on a 5-DOF system and an experimental investigation on a multi-story building model, being found that the algorithm could assess the condition of a structure in a more quantifiable manner over the traditional impedance approaches. Some issues that need close attention were identified: (i) the robustness of the proposed algorithm against environmental condition changes should be improved; (ii) different damage sensitive features could be used, such as relative and/or absolute changes in exogenous or auto-regressive $A R X$ coefficients; (iii) a prior curve fitting on the impedance data should be performed before constructing the $A R X$ model in order to minimize the effect of leakage in the frequency response measurements; (iv) the differentiating process involved in feature extraction often led to amplifications of existing noise in data; (v) the selection of proper EVS distribution for each data set and the evaluation of associated distribution parameters are still strongly based on an initial guess and on a trial-and-error method.

\subsection{Lamb waves}

An approach that has received much attention in the last few years uses the so called Lamb waves. Lamb waves are a type of elastic perturbation that can propagate on large areas in a free-free solid plate with low dispersion of energy, even in materials with a high attenuation ratio. This type of wave was first described in theory by Lamb (1917), though he has never tried to produce them. Alleyne and Cawley (1992) were among the first to discuss interaction of Lamb waves with defects for nondestructive testing. Saravanos et al. $\left(1994^{*}\right)$ presented a procedure for delamination detection in composite materials using Lamb Waves and embedded piezoelectric sensors.

Kessler et al. (2002) sustain that the techniques using Lamb waves have proven to provide more information about damage type, severity and location than previously tested methods, namely those using FRFs, since Lamb waves are more sensitive to local structural defects. Piezoceramic patches were used to excite the first anti-symmetric Lamb wave $\left(A_{0}\right.$ mode). The PZT actuators were chosen due to their high force output at relatively low voltages and also due to their good response qualities at low frequencies. Kessler et al. (2002) explored the optimization of Lamb wave methods for damage detection in composite materials, covering the problems of choosing the appropriate actuating frequency, pulse shape and sensor geometry for Lamb wave application. Results were compared by performing a wavelet decomposition using the Morlet wavelet, and plotting the magnitude of the coefficients at the driving frequency. Besides the great capabilities of Lamb waves in damage detection and localization, these authors point out, as the major disadvantage of this method, that it has to be active, i.e., requires a voltage supply and function generating signal to be supplied. Another difficult requirement is the high data acquisition rate needed to gain useful signal resolution. Finally, the Lamb wave method should most likely be placed into a $S H M$ system in conjunction with another passive detection method, such as an $F R F$ method, in order to conserve power and data storage space and because the resulting data can be more difficult to interpret.

Su et al. (2002) state that noteworthy efforts have been made since the 1980's in the field of wave propagation based identification methods. Nevertheless, it is known that the propagation characteristics of Lamb waves are relatively complicated because of the dispersion phenomenon. These authors studied the interaction between the fundamental Lamb wave modes and delamination in carbon fibre-reinforced laminates. As such, $F E$ models and experimental models of a plate with a delamination were tested, using PZT wafers as sensors/actuators. Finally, the calculated and measured dynamic responses were processed with the wavelet transform-based analysis in the time-frequency domain for the damage evaluation purpose, which has proven to be very effective to diminish the influence of broadband noises and structural vibration patterns and that the response in the timefrequency space is considerably sensitive to the delamination location. 
Lee and Staszewski (2002) deal with acousto-ultrasonic wave propagation modeling techniques, focusing on two-dimensional wave interactions with defects in metallic structures.

Ricci et al. (2004) present a methodology for automatic damage identification and localization in composite structural components. The damage is inflicted in the form of impact damage, which identification is based on the calculation of a set of damage correlation indices obtained from the frequency analysis of the signals, obtained from PZT sensors, in the reference and damaged state of the structure. The main idea behind this approach is that elastic waves propagating from the site where they are generated to the location where the signals are sensed, carry information about the portion of the structure through which they have travelled. Elastic waves can be very sensitive to small local defects. An indicator of any change in the propagation characteristics of the wave can be given by:

$$
D_{i}=\left|1-\frac{\left\{{ }^{d} H_{i}\right\}^{T}\left\{{ }^{d} H_{i}\right\}}{\left\{H_{i}\right\}^{T}\left\{H_{i}\right\}}\right|
$$

where $D_{i}$ is the damage index evaluated at the sensor location $i$ and $\left\{H_{i}\right\}$ is the frequency response vector at location $i$. These authors argued that this damage index approach can be used for detection and, under certain conditions, characterization of degradation in aircraft, aerospace and civil structures and that the analysis of the waveform signals would provide information on the location and nature of small defects.

Sohn et al. (2004a) proceeded with the work developed by Sohn et al. (2004b) and proposed a multiscale structural health monitoring approach for detecting defects in composite structures by combining Lamb wave propagation, impedance-based methods and time reversal acoustics using a common active sensing system for local nondestructive evaluation. These authors mention that the ultrasonic research community has studied Lamb waves for the nondestructive evaluation of plates since the 1960s. They also define Lamb waves as mechanical waves corresponding to vibration modes of plates with a thickness on the same order of magnitude as the wavelength. In the presented study, the wave attenuation feature, identified using a wavelet based damage index, is used to locate the region of damage (Sohn et al. (2004b)). Damage was introduced by firing a small projectile with varying velocities at different locations on a graphite fibre square plate with epoxy matrix. It was found that the three methods studied can be complementary because they can use the same sensors/actuators, which in this case were commercially available thin films with embedded PZT sensors. For instance, while it was observed that the Lamb wave propagation method is effective for thin plates, the impedance method is more suitable for detecting damage near structural joints or connections.

On another point of view, Toyama and Okabe (2004) study the effects of tensile strain and transverse cracks in the Lamb waves propagation velocity in cross-ply FRP laminates, since the waves' propagation velocity is quite sensitive to changes in the in-plane stiffness of the laminates. It is noted that some composite materials, such as CFRP, exhibit non-linear stress-strain responses, which makes Lamb wave velocity based damage detection methods more complex when under external loading. The Lamb wave propagation velocity was measured on GFRP (glass fibre-reinforced plastics) and CFRP laminates during tensile tests and the elastic behavior was studied. These authors make two interesting observations: The first one is that it seems that measuring the first symmetric Lamb wave ( $S_{0}$ mode) velocity is a more accurate means of evaluating the elasticity of laminates than the tensile test. Secondly, it is observed that wave velocity depends both on damage and on the laminate elasticity. Finally, they state that one needs to know the laminate stiffness as a function of strain when under external loadings, for damage detection purposes.

Sundararaman et al. (2005) use sparse phased sensor/actuator arrays for online damage detection and localization on heterogeneous and homogeneous plates and discuss the theory of narrowband and broadband beamforming of propagating plate waves in damaged elastic media. According to these authors, a beamformer is a spatial-temporal filter that can be used to 'look' in the direction of transmitted signal while eliminating interference that cannot be removed through temporal filtering or carrier demodulation alone. Beaformers consist of sensor arrays that are used to extract directional 
damage signatures. The principle in which this method is based is equivalent to an acoustic impedance discontinuity in the solid medium, so that damage, either in the form of debonding, delamination, fiber breakage, matrix cracking or voids, can be detected, localized and quantified. Experimental evaluation of this procedure was carried out on glass/epoxy woven composite, steel and aluminium plates.

Other works which make use of Lamb waves for damage detection and $S H M$ have been published recently, such as Beadle et al. (2005), Fritzen and Mengelkamp (2005), Giurgiutiu et al. (2005), Hera et al. (2005), Konstantinidis et al. (2005), Lucero and Taha (2005), Nieuwenhuis et al. (2005) or Raghavan and Cesnik (2005).

\subsection{Neural Networks}

The use of neural networks on damage detection procedures and SHM has been motivated by the possibility of existence of different types and locations of damage within the same structure, thus making the damage detection a complicated process.

Hanagud and Luo (1997**) use three layer feed-forward neural networks to identify two different types of damage in GFRPs: delamination and stiffness reduction due to transverse cracks or impact damage. It is assumed that only one of these defects exists, and analytical models are built to predict the dynamic behavior of the structure considering various scenarios of damage. A main neuralnetwork identifies the type of damage present using a non-linear dynamic response criterion, which directs the problem to one of two sub-networks. Both these sub-networks use FRFs as inputs. Using the same beam as 'case-study' Luo and Hanagud (1997**) propose the dynamic learning rate steepest descent $(D S D)$ for training neural-networks, with the aim of increasing the learning convergence speed relative to the simple steepest descent method.

Krawczuk et al. $\left(2000^{* *}\right)$ present the results on the application of a genetic algorithm and a neural network to detect and locate delamination on a numerical model of a multi-layered GFRP beam. Two different procedures were followed to identify the damage location and size: the first is based on $F E$ model updating and on error localization; the second considers a set of possible damage scenarios (including damage type, location and size). These researchers use an objective function, based on changes on the first four natural frequencies and on the damage location assurance criterion (DLAC) proposed by Messina et al. (1992). The genetic algorithm converges after a reasonable number of generations, although these authors have considered that this procedure deserved future developments by including more processes that are observed in nature, e.g., elitism. Concerning the neural network, its performance was considerably poor for detecting the delaminated layer location across thickness, since they considered a relatively small population of delaminated number of cases for training.

Hatem et al. (2004) also apply genetic algorithms and neural networks for damage detection in CFRPs composite materials. Four types of damage were considered in the model of a cantilevered beam: (i) circular holes with different diameters and locations, (ii) delamination with different areas and locations and (iii) linear surface cracks and (iv) linear through cracks with different lengths, orientations and locations. Damage type is identified with the generalized regression network. A sub-network is especially conceived for each damage type, in an ensemble of five: the generalized regression network, the linear network, the back-propagation network with and without regularization and the radial basis network. These authors state that the generalized regression networks successfully classified damage type, with a success rate ranging from $85 \%$ to $98 \%$. After damage is classified, an appropriate neural network or genetic algorithm is run to detect the remaining damage parameters, namely location, size and, in the case of a crack, orientation. Damage size was predicted with good accuracy, but the results on damage position and orientation were not that accurate.

Zheng et al. (2004) combine computational mechanics and neural networks, in this case the backpropagation method, for prediction of delamination in CFRPs' beams. The neural network was trained with $F E$ models, which were designed assuming various delamination sizes and locations. As 
inputs, it used the first five natural frequencies. According to these researchers, the neural network correctly predicted delamination size and location, within a small error margin.

\subsection{Time-Frequency Analysis}

Zabel (2004) (2005a) (2005b) applies a wavelet-based damage indicator for damage detection on reinforced concrete structures, where one of the case-studies was the Z24-bridge in Switzerland already mentioned in this work. The indicator is based on the analysis of signal energy components in discrete time-scale domain. Normally, the wavelet coefficients of the impulse response function (IRF) have different contributions to the considered system response. Thus, if the excitation force is known, then it is easy to normalize the response relatively to the excitation force. Another normalization possibility is to relate each response to the response in a reference location, thus leading to the transmissibility function. According to this author, it is possible and adequate to consider the transmissibility functions and their wavelet decompositions in a context of SHM when the ambient excitation is unknown. However, it is noticed that the analysis so far is based on the assumption of similar excitations for all the observations, which means that further research should be done to evaluate how this restriction can be surpassed without the need of a known excitation.

Savov and Wenzel (2005) use a wavelet approach in order to locate damage in civil infrastructures, based on the system's acceleration time history responses. A FE model of a three story shear-resisting frame excited by white noise ground acceleration and a prestressed reinforced concrete test beam under impact loading conditions were used as test structures. The first level fast wavelet decomposition of both the undamaged and actual measurements was applied using the Haar mother wavelet, and the approximation and detail coefficients were obtained. Reconstruction of the actual system response was accomplished by a cross combination of the approximation coefficients of the undamaged structure with the detail coefficients of the actual measurement. The sensitive feature is defined as the standard deviation of the error between this reconstructed signal and the actual measured signal. This method is based on the premise that the detail coefficients carry information about the local structural integrity in the time history response at the damaged sites. An advantaged of this method is that one does not need to know the excitation mechanism, since it is entirely based on the measured responses. However, damage location is compromised by the sensor mesh refinement. Extension of this approach to quantification of damage, to prediction of remaining structural life and to evaluation of more complex structures, varying operational and environmental conditions and nonlinear damage phenomena are issues to which these authors will give further attention.

Li, B. et al. (2005) present a methodology to detect crack location and size in a beam, which takes advantage of wavelet finite element methods (WFEM). The idea of the WFEM is close to the traditional $F E$ method to discretize a body into wavelet finite elements which are interconnected at nodal points on the element boundaries. Some of the advantages of WFEM over FE method for modal analysis of crack problems are pointed out. The natural frequencies of the beam with various crack locations and sizes are obtained, through the use of a WFEM, and used as features in the damage detection process. The accuracy of the method was tested on the experimental data of a beam studied by Silva, J. M. M. and Gomes (1990*). Finally, they believe that this procedure can be easily extended to complex structures with multiple cracks.

\subsection{Hilbert Transform}

Testa (2005) argues that the Hilbert-Huang transform (HHT) is very useful for non-stationary, nonzero mean and non-linear real signals. The HHT makes an Empirical Mode Decomposition (EMD) of the time signal into narrow band components with zero mean, in which each component is called an Intrinsic Mode Function $(I M F)$. Contrary to the $F F T$, these components do not have a specific 
analytical representation, but each component can be associated to a physical meaning, i.e., the components are related to the mode shapes and damage existence.

Lin, S. et al. (2005) use the technique of $H H T$ on the phase I $I A S C^{1}-A S C E^{2}$ benchmark problem for $S H M$. This benchmark has been developed to make easy the side-by-side comparison of various analysis techniques for the damage identification of structures on a common basis. The scale-model structure is a $3.6 \mathrm{~m}$ high four-story steel frame with $2.5 \times 2.5 \mathrm{~m}^{2}$ section area. Johnson, E. A. et al. (2004) present two analytical models of the structure: one is a 12-DOF shear-building model, the other a 120-DOF model, both finite element based. Based on the noisy acceleration data due to ambient excitation, Lin, S. et al. (2005) affirm that the HHT is capable of identifying natural frequencies, damping ratios, mode-shapes, stiffness matrix and damping matrix of a structure with a reasonable accuracy. Damage has been identified by comparing each floor stiffness before and after introducing damage. Simulation results show that the $H H T$ technique can detect, locate and quantify damage with good accuracy. Finally, these authors acknowledge the fact that, despite in the current benchmark model normal modes are assumed to exist, the technique can be used as well on linear structures with complex eigenproperties, such as in Yang et al. (2003).

Zhang et al. (2005) present the implementation of a method for nonlinear, nonstationary data processing, namely the $H H T$ in traditional vibration-based approaches to characterize structural damage. Also, the HHT is compared to the Fourier transfer function technique in detecting local damage with a computer model and experiments in two pile foundations of the Trinity River Relief (TRR) bridge in Texas, USA. The HHT analysis showed a more significant frequency downshift than Fourier-based approaches for measurements made near the damage location. These authors observed one aspect that although only applicable to very specific structures, like bridges, has its interest: by selecting two or more similar structural members (e.g., two of four columns in a bridge with the same size, cross section, and materials), data from a reference state may be avoided if only one of these members have experienced damage.

Shi and Law (2005a) (2005b) present a HHT-based technique for parameter identification (stiffness and damping) in damage detection for, respectively, linear time-varying discrete dynamic systems and nonlinear systems. Both procedures are tested with the use of analytical models in free vibration. Shi and Law (2005a) identify the non-linear system using a so-called skeleton linear model (SLM), which has similar dynamic behavior to the corresponding nonlinear system.

\subsection{Principal Component Analysis and Singular Value Decomposition}

Santos et al. (1999) (2000) present a technique for the identification of damage on laminated composite structures using, as case study, a numerical simulation of a rectangular plate. The algorithm is formulated by considering the sensitivities of the orthogonality conditions of the mode shapes, which allow for the calculation of a damage parameter in each finite element. This damage parameter is directly related to the stiffness reduction on the damaged finite element. They argue that the proposed method allows for multiple damage detection and location. These authors formulate a set of $M=m(m+1) / 2$ linear independent equations with $N$ unknowns, where $m$ is the number of vibration modes and $N$ is the number of elements, based on the orthogonality condition sensitivities of the damaged structure. In the cases where $M \geq N$, the solution can efficiently be found by a GaussJordan elimination method, whereas if the system is under-determined, i.e., $M<N$, it is possible to find the $N-M$ family of solutions using the Singular Value Decomposition technique (SVD) (Golub and Van Loan (1983)). These authors argue that the proposed technique allows for an efficient

\footnotetext{
${ }^{1}$ International Association of Structural Control.

${ }^{2}$ American Society of Civil Engineers.
} 
quantification of damage on either small or larger areas and that this methodology is a promising tool for the research community working on experimental damage identification.

More recently, Santos et al. (2004) (2005) presented a damage identification technique based on FRFs sensitivities. Considering that a single-input unit force is applied to the $l^{\text {th }} D O F$ of both the undamaged and damaged structure, they show that:

$$
[H(\omega)][\Delta Z(\omega)]\left\{{ }^{d} H_{l}(\omega)\right\}=\left\{H_{l}(\omega)\right\}-\left\{{ }^{d} H_{l}(\omega)\right\}
$$

where $[\Delta Z(\omega)]=\left[{ }^{d} Z(\omega)\right]-[Z(\omega)]$ is the difference between the dynamic stiffness matrices of the damaged and undamaged structure and $\left\{H_{l}(\omega)\right\}$ is the $l^{\text {th }}$ column of the mobility matrix $[H(\omega)]$. After some mathematical manipulations, which involve a first-order Taylor expansion, the above equation can be rewritten in a compact form, where the solution is found in a least-squares sense. In that formulation, it is implicit that one knows all DOFs of the damaged structure, which is not feasible in practice since rotational DOFs are very difficult to obtain experimentally, as can be seen, for example, in Montalvão et al. (2004a) (2004b). Consequently, the unknown DOFs of the damaged structure should be determined using an expansion of the measured DOFs. For example, Santos et al. (2003a) (2003b) propose the use of either the static or dynamic expansions for this purpose. Santos et al. (2004) (2005) realize that the mobility matrices should be computed with at least three times the number of natural frequencies and mode shapes contained in the frequency range of interest. On the other hand, they observed that the best identification results are obtained at lower frequency ranges. Also, for small damage, the errors are the main influence in the identification quality, whereas for large damage the incompleteness becomes the most important factor. These authors have also used a procedure for the weighting and elimination of equations, based on Ren and Beards (1995), once the solution depends not only on the quality of the FRF measurements but also on the frequencies and coordinates in which the vibration amplitude is larger. Finally, it is argued that this technique presents better results than those obtained when using a technique based on modal data sensitivities.

Bernal (2002b) use the Damage Locating Vector (DLV) approach to locate damage, using as casestudy the 4-story steel frame building of the phase II IASC-ASCE benchmark problem. The proposed damage characterization strategy is grounded in a cascade methodology that contains the following modules: (i) compression of the measured data and identification (stochastic state-space realization); (ii) extraction of flexibility proportional matrices; (iii) localization of damage using the DLV approach and (iv) quantification of damage. Concerning the DLV, this is a theoreticaly based technique for mapping changes in flexibility to the spatial distribution of damage. According to Bernal $\left(2000^{* *}\right)$ (2002a), the DLVs are a set of vectors that have the property of inducing stress fields whose magnitude is zero in the damaged elements. Consider (i) a system that can be treated as linear in the undamaged and damaged states, and that has flexibility matrices $F_{U}$ and $F_{D}$ respectively at $m$ sensor locations, and (ii) assume there are a number of load vectors, defined in the sensor coordinates, which produce identical deformations at the sensor locations both in the undamaged and damaged states. If the linearly independent vectors that satisfy this requirement are collected in a matrix $L$, and according to the compatibility of displacements, one may write:

$$
\left[F_{U}-F_{D}\right] L=[D F] L=0
$$

where $D F$ is computed from an $S V D$ of the flexibility matrix change of the system. Equation (31) can be satisfied either if $D F=0$ or if $D F$ is rank deficient and $L$ is a basis for the null space of $D F$. Bernal (2002a) shows that the first possibiliy implies that either there is no damage (though in practice no one ever computes $D F$ as identical to zero) or that damage is confined to a region of the structure where the stresses are zero for any loading sensor coordinates. On other words, the null space of the change in flexibility contains vectors that lead to identical displacements at the sensors locations both on the undamaged and damaged states. More developments on this issue for practice purposes are shown in Bernal $\left(2000^{* *}\right)(2002 \mathrm{a})$, such as selecting thresholds for the definition of the null space and the 'zero stress region', since in fact the stress level in any element will never be exactly zero. As a result, one may point out two drawbacks of this method: (i) it is not sensitive when damage does not introduce 
changes in the flexibility at the measurement points and (ii) the identification may be poor if the damage region is too large when compared to the number of sensors. However, it is worth mentioning that the authors claim that (i) it has the hability of detecting single and multiple damage scenarios, (ii) it can operate with an arbitrary number of sensors without resource to a DOF expansion or reduction strategies and (iii) the DLV vectors are computed strictly from the measured data without reference to a mathematical model of the system. Also, this method is equally aplicable from static measurements. Finally, since in Bernal (2002b) the inputs could not be measured, he used flexibility proportional matrices obtained following the procedure introduced by Bernal and Gunes (2002). This later is an extension of the DLV damage localization technique to the output-only case.

Yan et al. (2005a) propose a damage detection method for SHM under varying operational and environmental conditions, based on the Principal Component Analysis (PCA), also known as Karhunen-Loève transform or proper orthogonal decomposition. An advantage from the use of the $P C A$ is that it is not necessary to measure the environmental parameters because they are taken into account as embedded variables. This method relies on the principle that the measured feature changes due to environmental causes are different from those arising from structural damage. Novelty analysis on the residual errors provides a statistical indication of damage. The environmental conditions are assumed to have a linear effect on the vibration features. The application of this method to numerical and experimental data of a wooden bridge shows that different levels of damage can be correctly assessed independently from the environmental effects. This method is extended to the non-linear case by Yan et al. (2005b), in which a two step procedure is conceived, consisting on clustering the data space into several regions and then applying the $P C A$ in each local region. The local PCA-based damage detection method is applied, using vibration data measured in-situ over a one-year period, in the SHM of the Z24-bridge previously mentioned in this work. During the monitoring period measurements of the environmental parameters (temperature, wind, humidity, etc.) have been recorded. It was observed that the asphalt layer on the bridge surface plays a different role during warm and cold periods, thus causing non-linearity. For example, in an earlier work, Peeters and De Roeck (2000) established $A R X$ models, for the first four modes in order to obtain a good correlation between temperatures at selected locations and the natural frequencies of each mode, with the aim of analyzing different damage scenarios. A comparison has been made by Yan et al. (2004) between the work of Peeters and De Roeck (2000) and the one developed by Yan et al. (2005b), leading to the argument that by using the $P C A$-based damage detection method the problem becomes simpler, because only vibration features are needed to determine if the structure is damaged.

Vanlanduit et al. (2005) introduce the robust singular value decomposition (RSVD) for damage detection from measurements taken under different operational conditions, i.e., different excitation levels, geometrical uncertainties and surface treatments. This method is based on the SVD of a matrix $[H]=\left[H_{1}, \ldots, H_{N}\right]$, where $H_{1}, \ldots, H_{N}$ are observation features taken from $N$ experimental conditions. These features can be FRFs, response spectra or estimated modal parameters. The RSVD computes the $S V D$ of the intact structure from a set of observations of both intact and damaged structural states, possibly obtained under different conditions. The RSVD performance is then compared to the classical least-squares $S V D$ and to the iterative $S V D(I S V D)$. The experimental results show that the classical least-squares $S V D$ is not able to correctly classify damage because it gives an incorrect decomposition, when both damage and intact measurements are used to compute the subspace. This occurred because it is assumed that it is not known which observations are the healthy ones. If a set of observations belonging to the undamaged case is previously known, the authors agree that the $S V D$ performance will be comparable to that of the RSVD. It was also shown that the ISVD slightly improved the classification results, though it was not capable of identifying the smallest damage case considered. Finally, these researchers claim that the RSVD has proven to provide the most reliable results.

\subsection{Instrumentation}


Lin, M. (1999**) developed a printed circuit film layer of piezoceramic materials which can be embedded into composite structures during the production process. This film can support temperatures above the curing temperature for most composites. Lin, M. (1999**) argues that this interlamelar layer has little or no effects on the mechanical properties of composite structures.

Sundaresan et al. (2001) discuss the use of a scanning Laser Doppler vibrometer (SLDV) and piezoceramic materials for distributed sensing, with the purpose of evaluating the application of highly distributed sensors for wide area health monitoring of composite materials. The $S L D V$ is used for field tests as a non-contact quick check method to detect larger hidden damages, and the highly distributed embedded smart sensors are investigated for in situ real-time monitoring of composite structures. For the Laser vibrometer, two methods of damage detection were presented. The first, called boundary effect detection $(B E D)$, performs post processing of the operational deflection shapes (ODS), and, according to the authors, is somewhat akin to the wavelet method, thus allowing for small damage detection in the low frequency range. The second method, called operational deflection pattern recognition $(O D P R)$, is able to identify faults by evaluating irregularities in the vibration response patterns, avoiding the use of a reference pre-damage data.

Fritzen et al. (2002) designed an intelligent self-diagnosis system to detect the existence of delaminations in CFRP plate-like structures. The plate is instrumented with an array of four piezoceramic sensors and is excited with a random signal by means of a piezoceramic actuator. Different delamination severities were introduced by impacts at different velocities. As a damage indicator, they used the subspace-based fault detection algorithm, based on the work presented by Basseville et al. (2000). To determine the eigenfrequencies, damping and mode shape changes, the stochastic subspace identification method was used, following the approach proposed by Peeters and De Roeck (1999). They also performed a statistical $\chi^{2}$-test that allows assessing if the recent data fit the baseline data.

Deraemaeker and Preumont (2004a) (2004b) present an approach for vibration based damage detection, based on the use of a large number of sensors to which a programmable linear combiner is attached, using a simply supported beam. The linear combiner is programmed to work as a modal filter, i.e., the converted time-domain to frequency output content of the modal filter is used as the damage detection feature. First, these authors show that if local damage exists, then peaks will appear in the $F R F$ of the modal filter. Instead, if temperature changes are registered, the modal filter is shifted but its shape remains unchanged. Thus, the proposed approach allows distinguishing between local damage and global changes due to, e.g., the surrounding environment. For the case were the excitation forces are unknown, it is suggested to use the square root of the power spectral densities (PSD) instead of the FRFs, because the square root of the PSD has, in principle, the magnitude of the transfer function if the excitation force is white noise. It was demonstrated that this method allows for the detection of low levels of damage, as well as differentiating damage from temperature effects.

Lynch et al. (2004) develop an active wireless sensing unit to command a surface mounted PZT sensor in an aluminum plate. Low energy Lamb waves are introduced in the plate and the unit collects the signals measured by a second PZT sensor placed elsewhere on the plate surface. The potential of this unit to locally perform system identification analysis is illustrated by calculating $A R X$ models.

Sundaresan et al. (2004) study a structural health monitoring system that employs an embedded $A E$ sensor termed continuous sensor, first developed by Sundaresan et al. (2001). One of the advantages of this continuous sensor is that it avoids separate cabling and individual support electronics. They monitored fatigue crack growth in a fiberglass laminate specimen with two circular notches. They stated that the performance of the continuous sensor was superior to the traditional single node sensors. Also, they used wavelet maps to classify the $A E$ signals.

Nichols et al. (2005) report recent advances in both fields of sensing and signal processing with the aim of damage detection. A nine fibre-Bragg grating strain sensor network is used to measure the vibrational responses on a thin steel plate, subjected to successive growing saw-cut damage levels. The relationship between a reference (or undamaged) state to the actual (or damaged) state can be mathematically established when the structure is interrogated with a deterministic chaotic signal. This 
method relies on the principle that this function loses differentiability when damage exists. Thus, the use of the local Holder exponent is proposed as a means to quantify the differentiability of this function relating the undamaged to the damaged state responses. An algorithm to determine these quantities from time series data is also described.

Park, J. M. et al. (2005) evaluate the performance of different sensors for damage detection in glass fibre/epoxy composites through acoustic emission measurements. The analyzed sensors were: the PZT (piezoelectric lead-zirconate-titanate), the $P V D F$ (polyvinylidene fluoride) and the $P(V D F-T r F E)$ (poly(vinylidene fluoride-trifluoroethylene)). The $P V D F$ sensor was surface mounted and embedded on the composite structure, whereas the PZT was only surface mounted. It was observed that the embedded sensors are more sensitive to damage.

Motivated by the recent research advances, technological use and commercial activities in sensors and acquisition systems for monitoring, Bonfiglioli et al. (2005) study the electric strain gauges (ESG) measurement errors on FRP. They extended a theoretical deterministic approach developed in previous works to a probabilistic approach, with the aim of performing a sensitivity analysis of the variables that may result in errors on strain measurements. The experimental tests on several specimens made of different composite materials allowed to draw some conclusions with respect to the thickness of the resin, the ESG length, deviation angle and the sensors bonding glue. It was observed that the ESG length is the most important affecting factor and that short strain gauges are to avoid when the $F R P$ surface of the material is very rough. A very interesting conclusion stated by these authors is that the proposed model allows evaluating the Young modulus of the adhesive, which is very difficult to determine experimentally.

Qing et al. (2005) develop a hybrid piezoelectric/fibre optic (HyPFO) diagnostic system for quick non-destructive evaluation and long term health monitoring of aerospace vehicles and structures. Piezoelectrics are used as actuators and fibre gratings as sensors. One of the major advantages mentioned is the excellent actuator/sensor decoupling, since the transducers use different mechanisms for signal transmission (one is electrical and the other optical). Another advantage is that these transducers can be used for a multitude of measurements, i.e., the fibre-optic sensors can be used for temperature sensing, whereas the piezoelectric can be used for hydrogen sensing, and both can be used for acoustic emission measurements.

Wu et al. (2005) study the correlation between the mechanical and electrical properties of concrete beams strengthened with hybrid carbon fibre-reinforced polymer $(H C F R P)$. HCFRP sheets have simultaneously the aim of reinforcement and a built-in self-structural health monitoring function due to the electrical conduction and piezoresistivity of carbon fibres. The HCFRPs have self-diagnosis capabilities due to the relationships between strain/load and change in the electrical resistance. These authors observed that different damage stages, failure processes and ultimate failure modes of the $H C F R P$-strengthened concrete structures can be identified through the electrical resistance changes.

Castellini et al. (2005) produced a software for data acquisition, control of a scanning Laser Doppler vibrometer $(S L D V)$ and automatic measurement with the purpose of detecting delamination in composite plates, using as case study a delaminated composite panel made of 10 layers with aluminum sheets and glass fibre-reinforced epoxy prepreg (GLARE) for Airbus Deutschland aeronautical applications. These authors point out that the $S L D V$ has several advantages: it does not interfere with the structure, it has a high spatial resolution and sensitivity, it is adequate for high frequency analysis and it is suitable for in-operational conditions. The software uses a multivariate projection method, the Principal Component Analysis ( $P C A)$, to extract and display the systematic variation in a data matrix. Also, statistical processing aids to pre-process the measured data by reducing the amount of information. Consequently, multivariate analysis methods, like the $P C A$, offer the possibility of eliminating systematic effects such as noise. These researchers affirm that efforts are being endeavored in the search of optimal settings for the measurements, so that the number of measurement points is reduced. Also, some research is being made in the field of composite materials excitation, because it is important that the excitation energy is constant and high for the entire frequency band.

In a survey about the current smart sensor technologies for monitoring, Spencer Jr. et al. (2004) show that many efforts have been made on the use of remotely operated wireless-based systems, especially 
for damage detection in civil infrastructures. Since traditionally the impedance-base methods require the use of bulky and expensive analyzers, Grisso et al. (2005) present the initial steps on the development of an automatic wireless system for impedance-based damage detection, which they claim is cheaper, more eco-efficient and has smaller dimensions. The final purpose is to develop a sensor that can be permanently attached to the structure and provide meaningful data concerning structural integrity. Other features include utilizing energy from the ambient environment, exciting the host structure with a high-frequency excitation, analyzing the results and wirelessly providing the status of the structure to an end user. The hardware development of a prototype version of this sensor is described in detail. This sensor has been built and developed in the scope of the MEMS (micro electro-mechanical systems) augmented structural sensor (MASSpatch) joint-venture.

\subsection{Other Methods}

Afolabi $\left(1987^{*}\right)$ observed that anti-resonances shifts could be used to detect and locate damage. The dependence of anti-resonance frequencies on the measurement points is shown. Consequently, he observed that as the point of measurement gets closer to the location of the defect, fewer antiresonances are shifted from their original values, until one gets to the location of the defect, at which all the anti-resonances are as they were in the undamaged state. Although this is a quite interesting observation for the used beam model and for the shown simulation, one should not forget that stiffness relates at least two co-ordinates, which means that the interpretation of the results obtained in real structures may be more complicated. Also, he only formulated relationships for direct $F R F$ measurements, since for transfer functions this method may not work. The transfer $F R F$ relationships, which are very simple to derive following the same lines as Afolabi $\left(1987^{*}\right)$, can be found, for instance, in Montalvão (2003). More recently Wahl et al. (1999) presented a work in which they discuss the significance of antiresonances in experimental structural analysis for lightly damped linear systems. d'Ambrogio and Fregolent (2000) observed that the distribution of antiresonances may be significantly altered by small changes in the structural model. They use an updating technique that includes antiresonances in the definition of the output residual, showing that the use of antiresonances extracted from point FRFs allows for robust model updating procedures, mainly because antiresonances can be identified from experimental FRFs with much less error than mode shapes. Bamnios et al. (2002) monitored the change of the first antiresonance as a function of the measuring location along the beam and proposed a prediction procedure for transverse open crack localization in beams under bending vibrations. Dilena and Morassi (2004) use antiresonances to avoid the nonuniqueness of the damage location problem, which may occur in symmetrical beams with a single open crack when only frequency data is employed.

Zimmerman et al. (1995a*) discuss the implementation of the minimum rank perturbation theory (MRPT) based techniques to identify both the damage location and extent, using data from the NASA 8-bay dynamic scale model truss (DSMT) test-bed. In this study, the evaluation of damage location is included, as well as the selection of the number of vibration modes to measure, eigenvector and damage vector filtering to minimize the effects of measurement noise, filtering of dynamic residual decomposition among various property matrices (mass, damping and/or stiffness) when multiple property matrices are being updated and rank-estimation algorithms. Zimmerman et al. (1995b*) extend the $M R P T$ theory to determine matrix perturbations directly from $F R F$ data, discussing the benefits of this formulation. It is concluded that the MRPT algorithm implementation using FRFs simplifies the analysis by avoiding the need to perform modal parameter identification. Another interesting conclusion is that, contrary to what would be intuitively expected, the regions away from resonances and anti-resonances are those containing the richest data. More recently, Zimmerman (2005) investigated the effect of measurement noise on damage detection performance and sensitivity of the MRPT and resulting stiffness perturbation matrices. It was concluded that the use of linear sensitivity theory for estimation of the variance and standard deviation of each element in the damage vector and stiffness perturbation matrix is accurate by performing a Monte-Carlo simulation. These 
standard deviations were used to establish a threshold for damage existence and, after that, for damage location and extent assessment.

Worden et al. (2000**) present a study of a statistical method for damage detection using outlier analysis. These authors claim that the method not only allows for novelty detection (deviation from normal condition), but also suggests the optimal reduction of the dimension of the data set without compromising the diagnosis. A discordant outlier in a data set is an observation that appears inconsistent with the rest of the data. The discordance test is based on the Mahalanobis squared distance for multivariate data sets, where the threshold value to classify whether an observation is an outlier or not is determined using a Monte Carlo method. The method is tested in four different situations: transmissibility data in a simulated $3 D O F$ system, gearbox experimental data, Lamb wave experimental data on composite plates and ball-bearing experimental data. As conclusions, they point out that for the 3-DOF numerical model the method was unable to detect any of the $1 \%$ stiffness reduction cases as outliers, though for higher reduction cases the method correctly identified the outliers. However, it should be noted that some simplifications have been considered. First, it was considered that only a single outlier is present, which considerably simplifies the problem. On the other hand, when choosing the Mahalanobis squared distance, it is implicit that the normal condition set has Gaussian statistics. In the case of e.g. multi-modal distribution, these authors suggest other techniques such as the Kernel density estimation.

Gutschmidt and Cornwell (2001) present a false positive damage indication method (FPDIM) and apply it to experimental data for a plate that was progressively damaged. The purpose was to establish statistical bounds in order to distinguish damage from the natural variability associated with any measurement. The statistical bounds are defined using several sets of data from the baseline structure. The FPDIM was applied to two damage identification techniques that do not require a prior numerical model: the flexibility and the strain-energy methods. Using both of these methods, standard deviations $\sigma_{D I}$ of the damage indices $D I_{i}$ in each element $i$ for the undamaged structure were determined. A prediction interval is then calculated, where it is expected that the next data point will fall. Any point below that interval, will have a certain probability of failure. Eight damage cases were considered, and tests were carried out under the same experimental and environmental conditions. It was observed that application of the FPDIM to results from the strain-energy method eliminated false-positives. Nevertheless, when this method was applied to the flexibility method, false-positives occurred, i.e., the flexibility method successfully determined damage, but was unsuccessful in locating it.

Within the statistical pattern recognition paradigm established by Sohn et al. (2003), damage is in most cases identified by comparison between signals corresponding to two different structural states, one of them often corresponding to the undamaged state. Still, the operational and environmental variability, if not considered, may cause the unpredictable occurrence of either false-negatives or false-positives. In order to address this issue in the context of continuous online monitoring, Sohn et al. (2005) propose a technique, which does not rely on any past baseline signals, to assess damage in composite panels. The test setup consists of a square CFRP plate with surface mounted PZT patches, where delamination is introduced by impact damage with varying velocities. A time reversal concept of modern acoustics is adapted to Lamb wave guided propagation. According to the time reversal concept, an input signal can be reconstructed at an excitation point $\mathrm{A}$ if an output signal recorded at point $B$ is reemitted to the original source point $A$ after being reversed in a time domain. This process is referred to as the time reversibility of waves, and can be better understood by inspection of Fig. 1. 


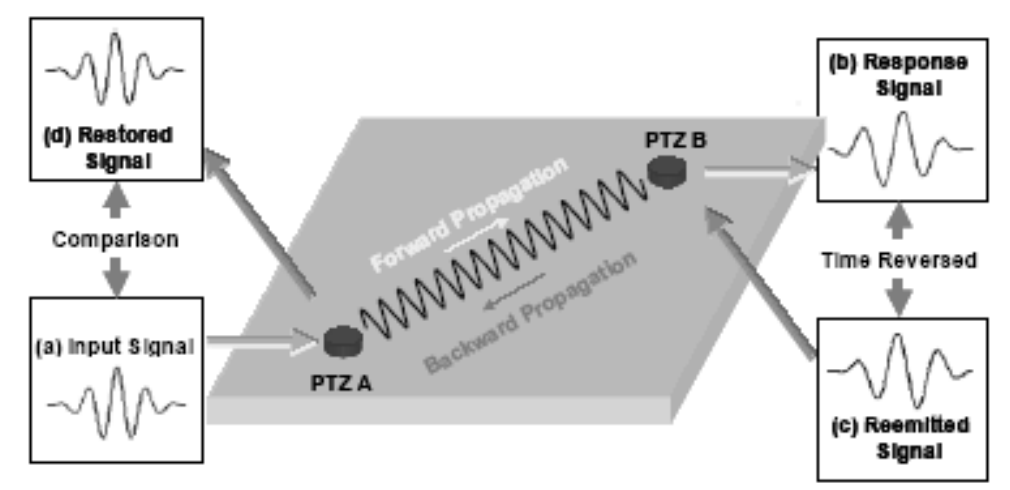

Fig. 1 Schematic concept of time reversal based damage identification (in Sohn et al. (2005)).

Damage detection is based on the fact that if a non-linear defect exists in the wave propagation path, time reversibility will no longer hold. A damage index based on the comparison between the original input waveform and the reconstructed signal is used to classify damage. A zero value means that time reversibility of Lamb waves is preserved and thus non-linear defects are present. Once the damage index value exceeds a threshold value, the state of the system is defined as damaged in a conventional sense. These authors employ the use of a consecutive outlier analysis (Barnett and Lewis (1994)) to establish the threshold value without resort to past reference data and to address the issue of multiple outliers. By using this approach, these authors successfully located and quantified damage in the test plate without relying on prior baseline signals.

According to Ibrahim et al. (1997) and to Li, H. C. H. et al. (2004) the introduction of the random decrement $(R D)$ technique is attributed to Cole (1968) (1973). Ibrahim et al. (1997) propose the vector random decrement (VRD) technique. Later, Asmussen et al. (1999) showed that the VRD can be considered as a generalization of the $R D$. Rodrigues et al. (2004) explored the idea of estimating the spectral densities as the Fourier transform of the $R D$ functions for the application of frequency domain output-only modal identification methods. Li, H. C. H. et al. (2004) investigate the potential of the $R D$ technique for damage detection in composite beams by introducing different levels of delamination at the midplane of the beam at various locations. The initial formulation consists of obtaining the freeresponse signature of the beam by processing its random response based upon the idea of a global average. This can be achieved by summing up many records of random responses in previously defined periods of time with appropriate criteria. This summation will result in a random decrement signature which minimizes the random component of the response. Each record can be seen as representing a linear system response composed of the overlapping of a step response, an impulse response, a random response and random noise. The step and impulse responses occur due to the initial displacement and initial velocity, respectively. When various records are summed up, the random components, including noise, and impulse responses, average to zero, thus only remaining the step response of the system. It is shown that the $R D$ signature is both affected by the delamination dimension and the sensor location. This may mean that damage detection can only be carried out successfully if a large database of $R D$ signatures is created from predicted defects and by the use of pattern recognition algorithms, such as neural networks. Li, H. C. H. et al. (2004) also note that the generation of such a database requires accurate modeling with appropriate treatment of structural damping which they say plays an important role in the vibration of composite materials.

Coppotelli et al. (2004) compare two different experimental techniques for damage identification purposes on composite plates. One approach is based on the dynamic displacement measurements of the plate surface, which are evaluated through the speckle fringe patterns as results of the electronic speckle pattern interferometry (ESPI), a high resolution holographic technique explored by Caponero et al. (2000) exploiting both interference and diffraction in optics. The other approach is based on experimental modal analysis techniques for eigenproperties extraction considering the complex exponent-based method (Ewins (1984), Maia and Silva (1997a)). The damage identification procedure used for the first procedure is based on the image correlation function $(I C F)$, which is the square root of the FDAC in the special case where the vectors involved are real and positive, whereas for the second case, they use the $M A C$. One of the two test-structures used to evaluate both techniques was a 
sandwich plate structure formed by two carbon fibre skins and by a honeycomb core in aluminum. This plate belongs to the Gamma-ray Large Area Space Telescope (GLAST), an international space mission aimed to collect gamma-ray data from the universe. Its launch is predicted for 2007.

In order to predict the remaining lifetime of a structure, Peil et al. (2004) acknowledge that the accumulated existing inherent damage must be first assessed. To accomplish this task on civil engineering structures, like bridges, they use either a theoretical model of the actions of the past or an experimental method using acoustic emissions to assess damage. In this last case, they take into account the entire transient signal, based on the assumption that different material damage processes lead to different transient signal forms, and the signals are assigned into a certain damage state class.

Lenzen (2005) presents a procedure for damage detection and localization, which was tested in a steel frame and two bridges, using the deterministic and stochastic subspace method for black box identification. If it is not practicable to set up physical equations of a system, black box modeling can be used to describe the input-output relation of the system, in accordance to the theory of systems and to the principle of cause-effect, in which systems are generally formulated as transfer functions. The black box model of both the intact and damaged systems, which have to be identified first, are compared and used to detect and localize system variations. This comparison is made by determining the so-called dynamic influence coefficients, which are used for the evaluation of the COMAC instead of normal modes. The theoretical backgrounds of black box modeling and subspace identification are described, as well as some of their limitations. Also, it is stated that the advantage of subspace identification is the physical weighting of the vibration modes with respect to the excitations.

Taylor and Zimmerman (2005) present a non model-based method to detect and locate structural damage (by evaluating linear stiffness changes) using load dependent Ritz vectors (Wilson et al. (1982)). They state that Ritz vectors are more sensitive to localized structural damage rather than mode shape vectors, which is an advantage when one cannot deal with a FEM of the structure (which can often occur in large civil structures applications) and because of the incompleteness problem. Also, tracking changes in mode shapes or shifts in the natural frequencies are often poor damage locators without the application of some model updating technique. Experiments were carried out on a steel bay welded frame structure being shown that Ritz vectors performed better over mode shape vectors in detecting small severities of localized damage without the use of a FEM.

Thien et al. (2005) present some guidelines for the development of a low-cost active-sensing based diagnostic system for pipeline structures. Integration of impedance-based and Lamb wave propagation methods in a common SHM sense is investigated. The impedance-based methods are used to detect and locate damage at the pipeline connection joints, while Lamb wave propagation methods are used to identify cracks and corrosion along the surface and through the thickness of the piping. Both techniques make use of the electromechanical coupling effects of piezoelectric-based active sensors, which in this case are small and non-intrusive macro-fibre composite patches. The procedure requires measurements in a reference state prior to damage. Minor defects can be detected due to operation at high-frequencies.

\section{PROGNOSIS}

Prognosis - or the prediction of a system's lifetime, that corresponds to the last level of the classification of damage detection methods introduced by Rytter $\left(1993^{*} * *\right)$ - is a matter that is traditionally approached by fracture mechanics and fatigue. However, considering the advantages that such a technology may carry to the security, economics and resource management fields, the scientific community that deals with vibration analysis is now beginning to take some interest in this area. Farrar et al. $\left(2003^{* *}\right)$ published a report whose purposes were to define the technology referred as prognosis. This work approaches, among others, the following topics: (i) a summary of the technologies and tools necessary to solve the prediction of a system's lifetime problem; (ii) a summary of the state of the art in damage prognosis; (iii) a generic approach to the problem, considering, however, that until that time 
all the prognosis solutions are directed to specific cases; (iv) the limitations inherent to such technologies; (v) a brief description of several applications in damage prognosis.

\section{FINAL REMARKS}

A survey of some of the representative advances in damage detection and Structural Health Monitoring in the last years, with special emphasis on composite materials - given the growing interest in the use of this kind of materials in several engineering applications - was hereby made.

Unfortunately, the more than two hundred works referred to in this article only represent a very small fraction of the universe of published works. Other works are not mentioned for several different reasons, namely because they use approaches that were not covered in this article. As an example, one may briefly mention some recent articles in which the excitation is made using the mathematical models of chaotic time series (Chang et al. (2004), Fasel and Todd (2005) or Olson et al. (2005)), techniques dealing with model updating (Yu et al. (2005) and De Roeck et al. (2005b)) or other diverse methods and applications (Cioara and Alampalli (2004), Liu and Chelidze (2005), Moura Jr. (2005), Nejad et al. (2005) or Law and Lu (2005)).

Currently, an immense number of techniques exist for the identification and location of damage. Because all the techniques have their own advantages and disadvantages, there is not a general algorithm that allows the resolution of all kinds of problems in all kinds of structures. Every technique tends to have damage related sensitivities, i.e., a very sensitive technique may lead to the arising of false-positives, while a less sensitive technique may lead to false-negatives, being this last case more problematic. Generally, only damage with a reasonable dimension can be detected. The quantification of damage and the remaining lifetime prediction are beyond any doubt the most difficult issues, the latter deserving a particular attention.

During the last years a considerable investment in the instrumentation techniques has been observed, namely in the ones that recur to SMART technologies for monitoring as well as in the use of high frequency waves, such as Lamb waves, for the detection of localized damage, i.e., with 'small dimension'.

Most of the traditional methods are based on the fact that damage leads to appreciable reduction in the rigidity of a structural element. However, one must not forget that a reduction in stiffness does not necessarily mean that there is a decrease in strength of the structural materials. This also represents one of the difficulties that Prognosis has to deal with in the future. Also, some authors argue that in some specific applications, combining static and dynamic experimental procedures is generally a good idea, since static and dynamic stiffness are different measurands. In structures made of composite materials there seems to be a tendency for the use of damping as the damage feature, once damping variations - associated to the dissipated energy - seems to be more sensitive to damage than the rigidity variations, mainly in what delamination is concerned. However, considering the more simple case of a crack, damping will only increase when the crack is opening, since that is the moment when there is more interaction between the faces of the crack. When the crack is fully opened (or fully closed) there is no friction, and thus damping remains with a low value. Also the evaluation of nonlinearity seems to be a promising technique in damage detection in composite materials, since the delamination may cause non-linear effects, due to friction.

The use of statistic parameters has also deserved a considerable attention, given the experimental errors, incompleteness, as well as the environmental and operational conditions, which may disguise the consequent damage alterations. The emergence of statistical pattern recognition techniques that allow the reduction of the number of used sensors is not totally implemented so far.

\section{REFERENCES}


1 Adams, R. D., Cawley, P., Pye, C. J. and Stone, B. J. (1978*), "A Vibration Technique for NonDestructively assessing the Integrity of Structures", Journal of Mechanical Engineering Science, Vol. 20, pp. 93-100.

2 Afolabi, D. (1987*), "An Anti-Resonance Technique for Detecting Structural Damage", Proceedings of the $5^{\text {th }}$ International Modal Analysis Conference (IMAC V), London, England, UK, pp. 491-495.

3 Aktan, A. E., Catbas, F. N., Grimmelsman, K. A. and Tsikos, C. J. (2000**), "Issues in Infrastructure Health Monitoring for Management", Journal of Engineering Mechanics, Vol. 126(7), pp. 711-724.

4 Alampalli, S. (2000), "Effects of Testing, Analysis, Damage and Environment on Modal Parameters", Mechanical Systems and Signal Processing, Vol. 14(1), pp. 63-74.

5 Allemang, R. J. and Brown, D. L. (1982), "A Correlation Coefficient for Modal Vector Analysis", Proceedings of the $1^{\text {st }}$ International Modal Analysis Conference (IMAC I), Orlando, Florida, USA, pp. 110116.

6 Alleyne, D. N. and Cawley, P. (1992), "The Interaction of Lamb Waves with Defects", IEEE Transactions on Ultrasonics, Ferroelectrics and Frequency Control, Vol. 39(3), pp. 381-397.

7 Andersen, P., Kirkegaard, P. H. and Brincker, R. (1997), "Filtering Out Environmental Effects in Damage Detection of Civil Engineering Structures", Proceedings of the $15^{\text {th }}$ International Modal Analysis Conference (IMAC XV), Orlando, Florida, USA, pp. 905-911.

8 Asmussen, J. C., Brincker, R. and Ibrahim, S. R. (1999), "Statistical Theory of the Vector Random Decrement Technique", Journal of Sound and Vibration, Vol. 226(2), pp. 329-344.

9 Bamnios, Y., Douka, E. and Trochidis, A. (2002), "Crack Identification in Beam Structures using Mechanical Impedance", Journal of Sound and Vibration, Vol. 256(2), pp. 287-297.

10 Barnett, V. and Lewis, T. (1994), "Outliers in Statistical Data", John Wiley \& Sohns.

11 Basseville, M., Abdelghani, M. and Benveniste, A. (2000), "Subspace-based Fault Detection Algorithms for Vibration Monitoring", Automatica, Vol. 36, pp. 101-109.

12 Battipede, M., Ruotolo, R. and Surace, C. (2001), "Damage Detection of Plate-like Structures", Proceedings of the $4^{\text {th }}$ International Conference on Damage Assessment of Structures (DAMAS 2001), Cardiff, Wales, UK, pp. 27-34.

13 Beadle, B. M., Hurlebaus, S., Jacobs, L. J. and Gaul, L. (2005), "Detection and Localization of Small Notches in Plates using Lamb Waves", Proceedings of the $23^{\text {rd }}$ International Modal Analysis Conference (IMAX XXIII), Orlando, Florida, USA, paper no. 96.

14 Bernal, D. (2000**), "Extracting Flexibility Matrices from State-Space Realizations", Proceedings of the European COST F3 Conference on System Identification and Structural Health Monitoring, Madrid, Spain, pp. 127-135.

15 Bernal, D. (2002a), "Load Vectors for Damage Localization", Journal of Engineering Mechanics, Vol. 128(1), pp. 7-14.

16 Bernal, D. (2002b), "Phase II of the ASCE Benchmark Study - Performance of the DLV Approach", Proceedings of the $1^{\text {st }}$ European Workshop on Structural Health Monitoring, Ecole Noemale Supérieure, Cachan, Paris, France, pp. 161-168.

17 Bernal, D. and Gunes, B. (2002), "Damage Localization in Output-Only Systems: A Flexibility Based Approach", Proceedings of the $20^{\text {th }}$ International Modal Analysis Conference (IMAC XX), Los Angeles, California, USA, pp. 1185-1191.

18 Berthelot, J. M. and Sefrani, Y. (2004), "Damping Analysis of Unidirectional Glass and Kevlar Fibre Composites", Composites Science and Technology, Vol. 64(9), pp. 1261-1278.

19 Betti, R. (2005), "Dynamic Methods for Damage Detection in Structures", Advanced Course on Dynamic Methods for Damage Detection in Structures, CISM (Centre International des Sciences Méchaniques), Udine, Italy.

20 Boltezar, M., Strancar, B. and Kuhelj, A. (1998), "Identification of Transverse Crack Location in Flexural Vibrations of Free-Free Beams", Journal of Sound and Vibration, Vol. 211(5), pp. 729-734.

21 Bonfiglioli, B., Strauss, A., Pascale, G. and Bergmeister, K. (2005), "Basic Study of Monitoring on Fibre Reinforced Polymers: Theoretical and Experimental Study", Smart Materials and Structures, Vol. 14, pp. 12-23.

22 Brincker, R. and Andersen, P. (2003a), "A Way of getting Scaled Mode Shapes in Output Only Modal Testing", Proceedings of the $21^{\text {st }}$ International Modal Analysis Conference (IMAC XXI), Kissimmee, Florida, USA, paper no. 141.

23 Brincker, R., Andersen, P., Kirkegaard, P. H. and Ulfkjaer, J. P. (1995a*), "Damage Detection in Laboratory Concrete Beams", Proceedings of the $13^{\text {th }}$ International Modal Analysis Conference (IMAC XIII), Nashville, Tennessee, USA, pp. 668-674.

24 Brincker, R., Kirkegaard, P. H., Andersen, P. and Martínez, M. E. (1995b*), "Damage Detection in an Offshore Structure", Proceedings of the $13^{\text {th }}$ International Modal Analysis Conference (IMAC XIII), Nashville, Tennessee, USA, pp. 661-667. 
25 Brincker, R., Ventura, C. E. and Andersen, P. (2003b), "Why Output-Only Modal Testing is a Desirable Tool for a Wide Range of Practical Applications", Proceedings of the $21^{\text {st }}$ International Modal Analysis Conference (IMAC XXI), Kissimmee, Florida, USA, paper no. 265.

26 Caponero, M. A., Pasqua, P., Paolozzi, A. and Peroni, I. (2000), "Use of Holographic Interferometry and Electronic Speckle Pattern Interferometry for Measurements of Dynamic Displacements", Mechanical Systems and Signal Processing, Vol. 14(1), pp. 49-62.

27 Carden, E. P. and Fanning, P. (2004), "Vibration Based Conditioning Monitoring: A Review", Structural Health Monitoring, Vol. 3(4), pp. 355-377.

28 Carvalho, R. J. S. (2003), "Resistência Residual de um Compósito de Matriz Epóxídica reforçado por Fibras de Carbono após Reparação", PhD Thesis, Instituto Superior Técnico, Technical University of Lisbon, Portugal (in Portuguese).

29 Castellini, P., Willemann, D. P. and Revel, G. M. (2005), "Application of a Laser Doppler Vibrometry for Structural Diagnostics on Composite Panels", Proceedings of the $23^{\text {rd }}$ International Modal Analysis Conference (IMAC XXIII), Orlando, Florida, USA, paper no. 371.

30 Cawley, P. (1997**), "Long Range Inspection of Structures Using Low Frequency Ultrasound", Proceedings of the $2^{\text {nd }}$ International Conference on Structural Damage Assessment using Advanced Signal Processing Procedures (DAMAS 97), Sheffield, England, UK, pp. 1-17.

31 Cawley, P. and Adams, R. D. (1979*), "The Location of Defects in Structures from Measurements of Natural Frequencies", Journal of Strain Analysis for Engineering Design, Vol. 14(2), pp. 49-57.

32 Chang, L. Y., Erickson, K. A., Lee, K. G. and Todd, M. D. (2004), "Structural Damage Detection using Chaotic Time Series Excitation", Proceedings of the $22^{\text {nd }}$ International Modal Analysis Conference (IMAC XXII), Dearborn, Michigan, USA, paper no. 221.

33 Choi, S. and Stubbs, N. (2004), "Damage Identification in Structures using the Time-Domain Response", Journal of Sound and Vibration, Vol. 275, pp. 577-590.

34 Cioara, T. G. and Alampalli, S. (2004), "Considerations on Damage Detection of a Structure using Vibration Test Data", Proceedings of the $22^{\text {nd }}$ International Modal Analysis Conference (IMAC XXII), Dearborn, Michigan, USA, paper no. 146.

35 Cole, H. A. (1968), "On-the-Line Analysis of Random Vibrations", AIAA Paper no. 68-288.

36 Cole, H. A. (1973), "On-line Failure Detection and Damping Measurement of Aerospace Structures by Random Decrement Signatures", NASA CR-2205.

37 Coppotelli, G., Di Conza, R., Mastroddi, F., Pascual, R. and Caponero, M. A. (2004), "Damage Identification in Composite Plates by Dynamic Displacement Measurements", Proceedings of the International Conference on Noise and Vibration Engineering (ISMA 2004), Leuven, Belgium, pp. 417-432.

38 Cornwell, P. J., Doebling, S. W. and Farrar, C. R. (1997), "Application of the Strain Energy Damage Detection Method to Plate-Like Structures", Proceedings of the $15^{\text {th }}$ International Modal Analysis Conference (IMAC XV), Orlando, Florida, USA, pp. 1312-1318.

39 d'Ambrogio, W. and Fregolent, A. (2000), "The use of Antiresonances for Robust Model Updating", Journal of Sound and Vibration, Vol. 236(2), pp. 227-243.

40 Davies, P. and Hammond, J. K. (1984), "A Comparison of Fourier and Parametric Methods for Structural Systems Identification", Journal of Vibration, Acoustics, Stress and Reliability in Design, Vol. 106, pp. 4048.

41 De Roeck, G. and Degrauwe, D. (2005a), "Damage Identification of the Lanaye Cable-Stayed Bridge", Proceedings of the $23^{\text {rd }}$ International Modal Analysis Conference (IMAC XXIII), Orlando, Florida, USA, paper no. 264

42 De Roeck, G., Teughels, A. and Reynders, E. (2005b), "Damage Identification of Civil Engineering Structures Based on Operational Modal Data", Proceedings of the $1^{\text {st }}$ International Operational Conference on Modal Analysis (IOMAC 2005), Copenhagen, Denmark, pp. 115-126.

43 Deraemaeker, A. and Preumont, A. (2004a), "Modal Filters for Vibration Based Damage Detection", Proceedings of the $2^{\text {nd }}$ European Workshop on Structural Health Monitoring, Forum am Deutschen Museum, Munich, Germany, pp. 844-851.

44 Deraemaeker, A. and Preumont, A. (2004b), "Modal Filters for Vibration Based Damage Detection", Proceedings of the International Conference on Noise and Vibration Engineering (ISMA 2004), Leuven, Belgium, pp. 501-514.

45 Dilena, M. and Morassi, A. (2004), "The use of Anti-Resonances for Crack Detection in Beams", Journal of Sound and Vibration, Vol. 276, pp. 195-214.

46 Doebling, S. W., Farrar, C. F., Prime, M. B. and Shevits, D. W. (1996**), "Damage Identification and Health Monitoring of Structural and Mechanical Systems from Changes in their Vibration Characteristics: A Literature Review", Los Alamos National Laboratory, USA.

47 Doebling, S. W., Farrar, C. R. and Prime, M. B. (1998**), "A Summary Review of Vibration-Based Damage Identification Methods", Shock and Vibration Digest, Vol. 30(2), pp. 91-105. 
48 Ewins, D. J. (1984), "Modal Testing: Theory and Practice", Research Studies Press, Ltd.

49 Farrar, C. R., Baker, W. E., Bell, T. M., Cone, K. M., Darling, T. W., Duffey, T. A., Eklund, A. and Migliori, A. (1994***), "Dynamic Characterization and Damage Detection in the I-40 Bridge over the Rio Grande", Los Alamos National Laboratory, USA.

50 Farrar, C. R., Doebling, S. W. and Nix, D. A. (2001), "Vibration-based Structural Damage Identification", Philosophical Transactions of the Royal Society of London Series A-Mathematical Physical and Engineering Sciences, Vol. 359(1778), pp. 131-149.

51 Farrar, C. R., Sohn, H., Hemez, F. M., Anderson, M. C., Bement, M. T., Cornwell, P. J., Doebling, S. W., Lieven, N., Robertson, A. N. and Schultze, J. F. (2003**), "Damage Prognosis: Current Status and Future Needs", Los Alamos National Laboratory, USA.

52 Farrar, C. R., Sohn, H. and Robertson, A. N. (2004), "Applications of Nonlinear System Identification to Structural Health Monitoring", Proceedings of the $2^{\text {nd }}$ European Workshop on Structural Health Monitoring, Forum am Deutshcen Museum, Munich, Germany, pp. 59-67.

53 Fasel, T. R. and Todd, M. D. (2005), "Effects of Data Acquisition and Generation on Using Upconverted Chaotic Waves for Active Structural Health Monitoring", Proceedings of the $23^{\text {rd }}$ International Modal Analysis Conference (IMAC XXIII), Orlando, Florida, USA, paper no. 210.

54 Fox, C. H. J. (1992), "The Location of Defects in Structures: A Comparison on the use of Natural Frequency and Mode Shape Data", Proceedings of the $10^{\text {th }}$ International Modal Analysis Conference (IMAC X), San Diego, California, USA, pp. 522-528.

55 Fritzen, C. P. and Mengelkamp, G. (2005), "In-Situ Damage Detection and Localization in Stiffened Structures", Proceedings of the $23^{\text {rd }}$ International Modal Analysis Conference (IMAC XXIII), Orlando, Florida, USA, paper no. 268.

56 Fritzen, C. P., Mengelkamp, G. and Guemes, A. (2002), "A CFRP Plate with Piezo-electric Actuators and Sensors as Self-Diagnosing Intelligent Structure", Proceedings of the International Conference on Noise and Vibration Engineering (ISMA 2002), Leuven, Belgium, pp. 185-191.

57 Galvin, P. and Dominguez, J. (2005), "Modal Identification of a Pedestrian Bridge by Output-Only Analysis", Proceedings of the $23^{\text {rd }}$ International Modal Analysis Conference (IMAC XXIII), Orlando, Florida, USA, paper no. 63.

58 Giurgiutiu, V., Buli, X. and Cuc, A. (2005), "Dual Use of Traveling and Standing Lamb Waves for Structural Health Monitoring", Proceedings of the $23^{\text {rd }}$ International Modal Analysis Conference (IMAC XXIII), Orlando, Florida, USA, paper no. 361.

59 Golub, G. H. and Van Loan, C. F. (1983), "Matrix Computations", North Oxford Academic.

60 Gomes, A. J. M. A. and Silva, J. M. M. (1992), "CRACAR - A Computer Program for Detection of Cracks in Structural Elements through the Variation of their Natural Frequencies", Internal Report, Faculdade de Ciências e Tecnologia, New University of Lisbon, Portugal (in Portuguese).

61 Grisso, B. J., Martin, L. A. and Inman, D. J. (2005), "A Wireless Active Sensing System for Impedancebased Structural Health Monitoring", Proceedings of the $23^{\text {rd }}$ International Conference on Modal Analysis (IMAC XXIII), Orlando, Florida, USA, paper no. 236.

62 Grisso, B. J., Peairs, D. M. and Inman, D. J. (2004), "Impedance-based Health Monitoring of Composites", Proceedings of the $22^{\text {nd }}$ International Modal Analysis Conference (IMAC XXII), Dearborn, Michigan, USA, paper no. 274.

63 Guillaume, P., Hermans, L. and Van der Auweraer, H. (1999), "Maximum Likelihood Identification of Modal Parameters from Operational Data", Proceedings of the $17^{\text {th }}$ International Modal Analysis Conference (IMAC XVII), Kissimmee, Florida, USA, pp. 1887-1893.

64 Guillaume, P., Parloo, E., Verboven, P. and De Sitter, G. (2002), "An Inverse Method for the Identification of Localized Excitation Sources", Proceedings of the $20^{\text {th }}$ International Modal Analysis Conference (IMAC XX), Los Angeles, California, USA, pp. 1382-1388.

65 Guillaume, P., Verboven, P. and Vanlanduit, S. (1998), "Frequency-Domain Maximum Likelihood Estimation of Modal Parameters with Confidence Intervals", Proceedings of the International Conference on Noise and Vibration Engineering (ISMA 23), Leuven, Belgium, pp. 359-366.

66 Gutschmidt, S. and Cornwell, P. J. (2001), "Statistical Confidence Bounds for Structural Health Monitoring", Proceedings of the $19^{\text {th }}$ International Modal Analysis Conference (IMAC XIX), Kissimmee, Florida, USA, pp. 193-198.

67 Hamey, C. S., Lestari, W., Qiao, P. and Song, G. (2004), "Experimental Damage Identification of Carbon/Epoxy Composite Beams using Curvature Mode Shapes", Structural Health Monitoring, Vol. 3(4), pp. 333-353.

68 Hanagud, S. and Luo, H. (1997**), "Damage Detection and Health Monitoring based on Structural Dynamics", Structural Health Monitoring, Current Status and Perspectives, Stanford University, Palo Alto, California, USA, pp. 715-726. 
69 Hatem, T. M., Foutouh, M. N. A. and Negm, H. M. (2004), "Application of Genetic Algorithms and Neural Networks to Health Monitoring of Composite Structures", Proceedings of the $2^{\text {nd }}$ European Workshop on Structural Health Monitoring, Forum am Deutschen Museum, Munich, Germany, pp. 616-623.

70 He, J. and Ewins, D. J. (1985*), "Analytical Stiffness Matrix Correlation using Measured Vibration Modes", Modal Analysis: The International Journal of Analytical and Experimental Modal Analysis, Vol. 1(3), pp. 914.

71 Hearn, G. and Testa, R. B. (1991*), "Modal Analysis for Damage Detection in Structures", Journal of Structural Engineering, Vol. 117(10), pp. 3042-3062.

72 Hera, A., Shinde, A. and Hou, Z. (2005), "Issues in Tracking Instantaneous Modal Parameters for Structural Health Monitoring using Wavelet Approach", Proceedings of the $23^{\text {rd }}$ International Modal Analysis Conference (IMAC XXIII), Orlando, Florida, USA, paper no. 338.

73 Heylen, W., Lammens, S. and Sas, P. (1998), "Modal Analysis Theory and Testing", K. U. Leuven - PMA, Belgium, Section A.6.

74 Hiroshi, H., Hassan, M. S. A., Hatsukade, Y., Wakayama, S., Suemasu, H. and Kasai, N. (2005), "Damage Detection of C/C Composites using ESPI and SQUID Techniques", Composites Science and Technology, Vol. 65, pp. 1098-1106.

75 Ho, Y. K. and Ewins, D. J. (2000**), "On the Structural Damage Identification with Mode Shapes", Proceedings of the European COST F3 Conference on System Identification and Structural Health Monitoring Madrid, Spain, pp. 677-686.

76 Hunt, D. L. (1992), "Application of an Enhanced Coordinate Modal Assurance Criterion", Proceedings of the $10^{\text {th }}$ International Modal Analysis Conference (IMAC X), San Diego, California, USA, pp. 66-71.

77 Ibrahim, S. R., Asmussen, J. C. and Brincker, R. (1997), "Vector Triggering Random Decrement Technique for Higher Identification Accuracy", Proceedings of the $15^{\text {th }}$ International Modal Analysis Conference (IMACXV), Orlando, Florida, USA, pp. 502-509.

78 Jacob, P. J., Desforges, M. J. and Ball, A. D. (1997**), "Analysis of Suitable Wavelet Coefficients for Identification of the Simulated Failure of Composite Materials", Proceedings of the $2^{\text {nd }}$ International Conference on Structural Damage Assessment using Advanced Signal Processing Procedures (DAMAS 97), Sheffield, England, UK, pp. 31-40.

79 Jauregui, D. V. and Farrar, C. R. (1986a*), "Damage Identification Algorithms Applied to Numerical Modal Data from a Bridge", Proceedings of the $14^{\text {th }}$ International Modal Analysis Conference (IMAC XIV), Dearborn, Michigan, USA, pp. 119-125.

80 Jauregui, D. V. and Farrar, C. R. (1986b*), "Comparison of Damage Identification Algorithms on Experimental Modal Data from a Bridge", Proceedings of the $14^{\text {th }}$ International Modal Analysis Conference (IMAC XIV), Dearborn, Michigan, USA, pp. 1423-1429.

81 Johnson, E. A., Lam, H. F., Katafygiotis, L. S. and Beck, J. L. (2004), "The Phase I IASC-ASCE Structural Health Monitoring Benchmark Problem using Simulated Data", ASCE Journal of Engineering Mechanics, Vol. 130, pp. 3-15.

82 Johnson, T. J., Brown, R. L., Adams, D. E. and Schiefer, M. (2004), "Distributed Structural Health Monitoring with a Smart Sensor Array", Mechanical Systems and Signal Processing, Vol. 18, pp. 555-572.

83 Kessler, S. S., Spearing, S. M. and Atalla, M. J. (2002), "In-Situ Damage Detection of Composites Structures using Lamb Waves Methods", Proceedings of the $1^{\text {st }}$ European Workshop on Structural Health Monitoring, Ecole Noemale Supérieure, Cachan, Paris, France, pp. 374-381.

84 Keye, S., Rose, M. and Sachau, D. (2001), "Localizing Delamination Damages in Aircraft Panels from Modal Damping Parameters", Proceedings of the $19^{\text {th }}$ International Modal Analysis Conference (IMAC XIX), Kissimmee, Florida, USA, pp. 412-417.

85 Kim, B. H., Stubbs, N. and Park, T. (2005), "Flexural Damage Index Equations of a Plate", Journal of Sound and Vibration, Vol. 283, pp. 341-368.

86 Kim, B. S., Yoo, S. H. and Yeo, G. H. (2005), "Charaterization of Crack Detection on Gusset Plates using Strain Mode Shapes", Proceedings of the $23^{\text {rd }}$ International Modal Analysis Conference (IMAC XXIII), Orlando, Florida, USA, paper no. 150.

87 Kim, J. H., Jeon, H. S. and Lee, C. W. (1992*), "Application of the Modal Assurance Criteria for Detecting and Locating Structural Faults", Proceedings of the $10^{\text {th }}$ International Modal Analysis Conference (IMAC $X)$, San Diego, California, USA, pp. 536-540.

88 Kisa, M. (2004), "Free Vibration Analysis of a Cantilever Composite Beam with Multiple Cracks", Composites Science and Technology, Vol. 64, pp. 1391-1402.

89 Klein, L. A. (1999**), "Sensor and Data Fusion: Concepts and Application", SPIE Press.

90 Konstantinidis, G., Wilcox, P. and Drinkwater, B. (2005), "Damage Detection using a Distributed Array of Guided Wave Sensors", Proceedings of the $23^{\text {rd }}$ International Modal Analysis Conference (IMAC XXIII), Orlando, Florida, USA, paper no. 265. 
91 Krawczuk, M., Ostachowicz, W. and Kawiecki, G. (2000**), "Detection of Delaminations in Cantilevered Beams using Soft Computing Methods", Proceedings of the European COST F3 Conference on System Identification and Structural Health Monitoring, Madrid, Spain, pp. 243-252.

92 Kullaa (2002), "Elimination of Environmental Influences from Damage-Sensitive Features in a Structural Health Monitoring System", Proceedings of the $1^{\text {st }}$ European Workshop on Structural Health Monitoring, Ecole Noemale Supérieure, Cachan, Paris, France, pp. 742-749.

93 Kyriazoglou, C., Le Page, B. H. and Guild, F. J. (2004), "Vibration Damping for Crack Detection in Composite Laminates", Composites, Part A: Applied Sciences and Manufacturing, Vol. 35, pp. 945-953.

94 Lamb, H. (1917), "On Waves in an Elastic Plate", Proceedings of the Royal Society of London, Containing Papers of a Mathematical and Physical Character, Vol. 93(651), pp. 293-312.

95 Law, S. S. and Lu, Z. R. (2005), "Crack Identification in Beam from Dynamic Responses", Journal of Sound and Vibration, Vol. 285, pp. 967-987.

96 Lazarov, B. and Trendafilova, I. (2004), "An Investigation on Vibration-Based Damage Diagnosis in Thin Plates", Proceedings of the $2^{\text {nd }}$ European Workshop on Structural Health Monitoring, Forum am Deutschen Museum, Munich, Germany, pp. 76-82.

97 Le Page, B. H., Guild, F. J., Ogin, S. L. and Smith, P. A. (2004), "Finite Element Simulation of Woven Fabric Composites", Composites: Part A, Vol. 35, pp. 861-872.

98 Lee, B. C. and Staszewski, W. J. (2002), "Modelling of Acousto-ultrasonic Wave Interaction with Defects in Metallic Structures", Proceedings of the International Conference on Noise and Vibration Engineering (ISMA 2002), Leuven, Belgium, pp. 319-327.

99 Lenzen, A. (2005), "Identification of Mechanical Systems by Vibration Analysis for Health Monitoring and Damage Detection", Proceedings of the $1^{\text {st }}$ International Operational Modal Analysis Conference (IOMAC 2005), Copenhagen, Denmark, pp. 155-166.

100 Leontaritis, I. J. and Billings, S. A. (1985a), "Input Output Parametric Models for Non-Linear Systems .1. Deterministic Non-Linear Systems", International Journal of Control, Vol. 41(2), pp. 303-328.

101 Leontaritis, I. J. and Billings, S. A. (1985b), "Input Output Parametric Models for Non-Linear Systems .2. Stochastic Non-Linear Systems", International Journal of Control, Vol. 41(2), pp. 329-344.

102 Li, B., Chen, X. F., Ma, J. X. and He, Z. J. (2005), "Detection of Crack Location and Size in Structures using Wavelet Finite Element Methods", Journal of Sound and Vibration, Vol. 285, pp. 767-782.

103 Li, H. C. H., Weis, M., Herszberg, I. and Mouritz, A. P. (2004), "Damage Detection in a Fiber Reinforced Composite Beam using Random Decrement Signatures", Proceedings of the $2^{\text {nd }}$ European Workshop on Structural Health Monitoring, Forum am Deutschen Museum, Munich, Germany, pp. 1091-1098.

104 Liang, C., Sun, F. P. and Rogers, C. A. (1994), "An Impedance Method for Dynamic Analysis of Active Material System", Journal of Vibration and Acoustics, Vol. 116, pp. 121-128.

105 Lieven, N. A. J. and Ewins, D. J. (1988), "Spatial Correlation of Mode Shapes: The Coordinate Modal Assurance Criterion (COMAC)", Proceedings of the $6^{\text {th }}$ International Modal Analysis Conference (IMAX VI), Kissimmee, Florida, USA, pp. 690-695.

106 Lifshitz, J. M. and Rotem, A. (1969*), "Determination of Reinforcement Unbonding of Composites by a Vibration Technique", Journal of Composite Materials, Vol. 3, pp. 412-423.

107 Lin, M. (1999**), "Development of SMART Layer for Built-In Structural Diagnostics", Structural Health Monitoring 2000, Stanford University, Palo Alto, California, USA, pp. 603-611.

108 Lin, S., Yang, J. N. and Zhou, L. (2005), "Damage Identification of a Benchmark Building for Structural Health Monitoring", Smart Materials and Structures, Vol. 14, pp. 162-169.

109 Liu, M. and Chelidze, D. (2005), "Flow Variance Method for Damage Identification", Proceedings of the $23^{\text {rd }}$ International Modal Analysis Conference (IMAC XXIII), Orlando, Florida, USA, paper no. 188.

$110 \mathrm{Lu}$, Y. and Gao, F. (2005), "A Novel Time-Domain Auto-Regressive Model for Structural Damage Diagnosis", Journal of Sound and Vibration, Vol. 283, pp. 1031-1049.

111 Lucero, J. and Taha, M. M. R. (2005), "A Wavelet-Aided Fuzzy Damage Detection Algorithm for Structural Health Monitoring", Proceedings of the $23^{\text {rd }}$ International Modal Analysis Conference (IMAC XXIII), Orlando, Florida, USA, paper no. 78.

112 Luo, H. and Hanagud, S. (1997**), "Dynamic Learning Rate Neural Network Training and Composite Structural Damage Detection", AIAA Journal, Vol. 35(9), pp. 1522-1527.

113 Lynch, J. P., Sundararajan, A., Law, K. H., Sohn, H. and Farrar, C. R. (2004), "Piezoelectric Structural Excitation using a Wireless Active Sensing Unit", Proceedings of the $22^{\text {nd }}$ International Modal Analysis Conference (IMAC XXII), Dearborn, Michigan, USA, paper no. 157.

114 Maheri, M. R. and Adams, R. D. (2003), "Modal Vibration Damping of Anisotropic FRP Laminates using the Rayleigh-Ritz Energy Minimization Scheme", Journal of Sound and Vibration, Vol. 259(1), pp. 17-29.

115 Maia, N. M. M. (2001), "Detecção de Dano Estrutural por Análise Dinâmica", Habilitation Lecture, Instituto Superior Técnico, Technical University of Lisbon, Portugal (in Portuguese). 
116 Maia, N. M. M. and Silva, J. M. M. (1997a), "Theoretical and Experimental Modal Analysis", Research Studies Press, Ltd.

117 Maia, N. M. M., Silva, J. M. M., Almas, E. A. M. and Sampaio, R. P. C. (2003), "Damage Detection in Structures: from Mode Shape to Frequency Response Function Methods", Mechanical Systems and Signal Processing, Vol. 17(3), pp. 489-498.

118 Maia, N. M. M., Silva, J. M. M. and Sampaio, R. P. C. (1997b), "Localization of Damage using Curvature of the Frequency-Response-Functions", Proceedings of the $15^{\text {th }}$ International Modal Analysis Conference (IMAC XV), Orlando, Florida, USA, pp. 942-946.

119 Mares, C., Ruotolo, R. and Surace, C. (1999**), "Using Transmissibility Data to Assess Structural Damage", Proceedings of the $3^{\text {rd }}$ International Conference on Damage Assessment of Structures (DAMAS 99), Dublin, Ireland, pp. 236-245.

120 Matthews, F. L. (1999), "Damage in Fibre Reinforced Plastics; Its Nature, Consequences and Detection", Proceedings of the $3^{\text {rd }}$ International Conference on Damage Assessment of Structures (DAMAS 99), Dublin, Ireland, pp. 1-16.

121 Messina, A., Jones, I. A. and Williams, E. J. (1992), "Damage Detection and Localization using Natural Frequency Changes", Proceedings of the $1^{\text {st }}$ Conference on Identification, Cambridge, England, UK, pp. 6776.

122 Messina, A., Jones, I. A. and Williams, E. J. (1996), "Damage Detection and Localization using Natural Frequency Changes", Proceedings of the Conference on Identification in Engineering Systems, Swansea, Wales, UK, pp. 67-76.

123 Messina, A., Williams, E. J. and Contursi, T. (1998**), "Structural Damage Detection by a Sensitivity and Statistical-Based Method", Journal of Sound and Vibration, Vol. 216(5), pp. 791-808.

$124 \mathrm{Mevel,} \mathrm{L.} \mathrm{and} \mathrm{Goursat,} \mathrm{M.} \mathrm{(2004),} \mathrm{"A} \mathrm{Complete} \mathrm{Scilab} \mathrm{Toolbox} \mathrm{for} \mathrm{Output-Only} \mathrm{Identification",}$ Proceedings of the $22^{\text {nd }}$ International Modal Analysis Conference (IMAC XXII), Dearborn, Michigan, USA, paper no. 60.

125 Montalvão, D. (2003), "Determination of Rotational Terms of the Dynamic Response by means of Modal Analysis Techniques", MSc Thesis, Instituto Superior Técnico, Technical University of Lisbon, Portugal (in Portuguese).

126 Montalvão, D., Ribeiro, A. M. R., Maia, N. M. M. and Silva, J. M. M. (2004a), "Estimation of the Rotational Terms of the Dynamic Response Matrix", Shock and Vibration, Vol. 11(3-4), pp. 333-350.

127 Montalvão, D., Ribeiro, A. M. R., Maia, N. M. M. and Silva, J. M. M. (2004b), "On the Estimation of Frequency Response Functions", Proceedings of the International Conference on Noise and Vibration Engineering (ISMA 2004), Leuven, Belgium, pp. 2771-2785.

128 Morais, W. A., Monteiro, S. N. and d'Almeida, J. R. M. (2005), "Effect of the Laminate Thickness on the Composite Strength to Repeated Low Energy Impacts", Composite Structures, Vol. 70, pp. 223-228.

129 Moura Jr., J. R. V. (2005), "Damage Detection Techniques for Aeronautic Structures", Proceedings of the $23^{\text {rd }}$ International Modal Analysis Conference (IMAC XXIII), Orlando, Florida, USA, paper no. 101.

130 Moura Jr., J. R. V. and Steffen Jr., V. (2004), "Impedance-based Health Monitoring: Frequency Band Evaluation", Proceedings of the $22^{\text {nd }}$ International Modal Analysis Conference (IMAC XXII), Dearborn, Michigan, USA, paper no. 161.

131 Nayfeh, S. A. (2004), "Damping of Flexural Vibration in the Plane of Lamination of Elastic-viscoelastic Sandwich Beams", Journal of Sound and Vibration, Vol. 276(3-5), pp. 689-711.

132 Nejad, F. B., Rahai, A. and Esfandiari, A. (2005), "A Constrained Structural Damage Detection Method Using Static Noisy Data and Natural Frequencies", Proceedings of the $23^{\text {rd }}$ International Modal Analysis Conference (IMAC XXIII), Orlando, Florida, USA, paper no. 127.

133 Nichols, J. M., Moniz, L., Seaver, M. and Trickey, S. T. (2005), "Use of Holder Exponents and Fiber Optic Sensing for Detecting Damage in an Experimental Plate Structure", Proceedings of the $23^{\text {rd }}$ International Modal Analysis Conference (IMAC XXIII), Orlando, Florida, USA, paper no. 197.

134 Nieuwenhuis, J. H., Neumann, J. J., Greve, D. W. and Oppenheim, I. J. (2005), "Simulation and Testing of Transducers for Lamb Wave Generation", Proceedings of the $23^{\text {rd }}$ International Modal Analysis Conference (IMAC XXIII), Orlando, Florida, USA, paper no. 216.

135 Olson, C. C., Overbey, L. A. and Todd, M. D. (2005), "A Comparison of State-Space Attractor Features in Structural Health Monitoring", Proceedings of the $23^{\text {rd }}$ International Modal Analysis Conference (IMAC XXIII), Orlando, Florida, USA, paper no. 209.

136 Ostachowicz, W. and Zak, A. (2004), "Vibration of a Laminated Beam with Delamination including Contact Effects", Shock and Vibration, Vol. 11, pp. 157-171.

137 Pandey, A. K., Biswas, M. and Samman, M. M. (1991*), "Damage Detection from Changes in Curvature Mode Shapes", Journal of Sound and Vibration, Vol. 145(2), pp. 321-332.

138 Pandit, S. W. and Metha, N. P. (1985), "Data Dependent System Approach to Modal Analysis Via State Space", ASME paper No. 85-WA/DSC-1. 
139 Park, G., Cudney, H. and Inman, D. J. (1999**), "Impedance-Based Health Monitoring Technique for Civil Structures", Structural Health Monitoring 2000, Stanford University, Palo Alto, California, USA, pp. 523532.

140 Park, G., Rutherford, A. C., Sohn, H. and Farrar, C. R. (2005), "An Outlier Analysis Framework for Impedance-based Structural Health Monitoring", Journal of Sound and Vibration, Vol. 286, pp. 229-250.

141 Park, G., Sohn, H., Farrar, C. R. and Inman, D. J. (2003), "Overview of Piezoelectric Impedance-Based Health Monitoring and Path-Forward", Shock and Vibration Digest, Vol. 35(6), pp. 451-463.

142 Park, J. M., Kong, J. W., Kim, D. S. and Yoon, D. J. (2005), "Nondestructive Damage Detection and Interfacial Evaluation of Single-Fibers/Epoxy Composites using PZT, PVDF and P(VDF-TrFE) Copolymer Sensors", Composites Science and Technology, Vol. 65, pp. 241-256.

143 Park, N. G. and Park, Y. S. (2003), "Damage Detection using Spatially Incomplete Frequency Response Functions", Mechanical Systems and Signal Processing, Vol. 17(3), pp. 519-532.

144 Park, Y. S., Park, H. S. and Lee, S. S. (1988*), "Weighted-Error-Matrix Application to Detect Stiffness Damage by Dynamic-Characteristic Measurement", Modal Analysis: The International Journal of Analytical and Experimental Modal Analysis, Vol. 3(3), pp. 101-107.

145 Parloo, E., Guillaume, P. and Van Overmeire, M. (2003), "Damage Assessment Using Mode Shape Sensitivities", Mechanical Systems and Signal Processing, Vol. 17(3), pp. 499-518.

146 Parloo, E., Vanlanduit, S., Guillaume, P. and Verboven, P. (2002b), "Increased Reliability of Referencebased Damage Identification Techniques by using Output-only Data", Proceedings of the International Conference on Structural Dynamics Modelling, Test, Analysis, Correlation and Validation, Funchal, Madeira, Portugal, pp. 137-146.

147 Parloo, E., Vanlanduit, S., Guillaume, P. and Verboven, P. (2004), "Increased Reliability of Referencebased Damage Identification Techniques by using Output-only Data", Journal of Sound and Vibration, Vol. 270(4-5), pp. 813-832.

148 Parloo, E., Verboven, P., Guillaume, P. and Van Overmeire, M. (2002a), "Sensitivity-based Operational Mode Shape Normalization", Mechanical Systems and Signal Processing, Vol. 16(5), pp. 757-767.

149 Pascual, R., Golinval, J. C. and Razeto, M. (1997), "A Frequency Domain Correlation Technique for Model Correlation and Updating", Proceedings of the $15^{\text {th }}$ International Modal Analysis Conference (IMAC XV), Orlando, Florida, USA, pp. 587-592.

150 Patil, D. P. and Maiti, S. K. (2005), "Experimental Verification of a Method of Detection of Multiple Cracks in Beams based on Frequency Measurements", Journal of Sound and Vibration, Vol. 281, pp. 439-451.

151 Peairs, D. M., Park, G. and Inman, D. J. (2005), "Impedance-based SHM Modeling using Spectral Elements and Circuit Analysis", Proceedings of the $23^{\text {rd }}$ International Modal Analysis Conference (IMAC XXIII), Orlando, Florida, USA, paper no. 232.

152 Peeters, B. and De Roeck, G. (1999), "Reference-based Stochastic Subspace Identification for Output-only Modal Analysis", Mechanical Systems and Signal Processing, Vol. 13(6), pp. 855-878.

153 Peeters, B. and De Roeck, G. (2000), "One Year Monitoring of the Z24-Bridge: Environmental Influences versus Damage Events", Proceedings of the $18^{\text {th }}$ International Modal Analysis Conference (IMAC XVIII), San Antonio, Texas, USA, pp. 1570-1576.

154 Peil, U., Mehdianpour, M., Frenz, M. and Weilert, K. (2004), "Determination of the Inherent Damage of Older Structures", Proceedings of the $2^{\text {nd }}$ European Workshop on Structural Health Monitoring, Forum am Deutschen Museum, Munich, Germany, pp. 243-250.

155 Penny, J. E. T., Wilson, D. A. L. and Friswell, M. I. (1993*), "Damage Location in Structures using Vibration Data", Proceedings of the $11^{\text {th }}$ International Modal Analysis Conference (IMAC XI), Kissimmee, Florida, USA, pp. 861-867.

156 Pirner, M. and Urushadze, S. (2004), "Dynamic Response as a Tool for Damage Identification", International Applied Mechanics, Vol. 40(5), pp. 487-505.

157 Qin, Q. and Zhang, W. (1998), "Damage Detection of Suspension Bridges", Proceedings of the $16^{\text {th }}$ International Modal Analysis Conference (IMAC XVI), Santa Barbara, California, USA, pp. 945-951.

158 Qing, X., Kumar, A., Zhang, C., Gonzalez, I. F., Guo, G. and Chang, F. K. (2005), "A Hybrid Piezoelectric/Fiber Optic Diagnostic System for Structural Health Monitoring", Smart Materials and Structures, Vol. 14, pp. 98-103.

159 Raghavan, A. and Cesnik, C. E. S. (2005), "Analytical Models for Lamb-Wave Based Structural Health Monitoring", Proceedings of the $23^{\text {rd }}$ International Conference on Modal Analysis (IMAC XXIII), Orlando, Florida, USA, paper no. 289.

160 Randall, R. B. (2002), "State of the Art in Monitoring Rotating Machinery", Proceedings of the International Conference on Noise and Vibration Engineering (ISMA 2002), Leuven, Belgium, pp. $1457-$ 1477.

161 Ratcliffe, C. P. (2000), "A Frequency and Curvature based Experimental Method for Locating Damage in Structures", Journal of Vibration and Acoustics, Vol. 122, pp. 324-329. 
162 Ratcliffe, C. P. and Bagaria, W. J. (1998), "A Vibration Technique for Locating Delamination in a Composite Beam", AIAA Journal, Vol. 36(6), pp. 1074-1077.

163 Ren, Y. and Beards, C. F. (1995), "Identification of Joint Properties of a Structure using FRF Data", Journal of Sound and Vibration, Vol. 186(4), pp. 567-587.

164 Ricci, F., Banerjee, S. and Mal, A. K. (2004), "Health Monitoring of Composite Structures using Wave Propagation Data", Proceedings of the $2^{\text {nd }}$ European Workshop on Structural Health Monitoring, Forum am Deutschen Museum, Munich, Germany, pp. 1035-1042.

165 Rodrigues, J., Brincker, R. and Andersen, P. (2004), "Improvement of Frequency Domain Output-Only Modal Identification from the Application of the Random Decrement Technique", Proceedings of the $22^{\text {nd }}$ International Modal Analysis Conference (IMAC XXII), Dearborn, Michigan, USA, paper no. 92.

166 Ruotolo, R. and Surace, C. (1997**), "Damage Detection Using Singular Value Decomposition", Proceedings of the $2^{\text {nd }}$ International Conference on Structural Damage Assessment using Advanced Signal Processing Procedures (DAMAS 97), Sheffield, England, UK, pp. 87-96.

167 Rytter, A. (1993***), "Vibration Based Inspection of Civil Engineering Structures", PhD Thesis, Aalborg University, Denmark.

168 Safak, E. (1991), "Identification of Linear Structures using Discrete-Time Filters", Journal of Structural Engineering, Vol. 117(10), pp. 3064-3085.

169 Salawu, O. S. and Williams, C. (1994*), "Damage Location using Vibration Mode Shapes", Proceedings of the $12^{\text {th }}$ International Modal Analysis Conference (IMAC XII), Honolulu, Hawaii, USA, pp. 933-939.

170 Sampaio, R. P. C. and Maia, N. M. M. (2004), "On the Detection and Relative Damage Quantification Indicator", Proceedings of the $2^{\text {nd }}$ European Workshop on Structural Health Monitoring, Forum am Deutschen Museum, Munich, Germany, pp. 757-766.

171 Sampaio, R. P. C., Maia, N. M. M. and Silva, J. M. M. (1999), "Damage Detection using the FrequencyResponse-Function Curvature Method", Journal of Sound and Vibration, Vol. 226(5), pp. 1029-1042.

172 Sampaio, R. P. C., Maia, N. M. M. and Silva, J. M. M. (2003), "The Frequency Domain Assurance Criterion as a Tool for Damage Identification", Proceedings of the $5^{\text {th }}$ International Conference on Damage Assessment of Structures (DAMAS 2003), Southampton, England, UK, pp. 69-76.

173 Sampaio, R. P. C., Maia, N. M. M., Silva, J. M. M. and Ribeiro, A. M. R. (2000), "On the use of Transmissibility for Damage Detection and Location", Proceedings of the European COST F3 Conference on System Identification and Structural Health Monitoring, Madrid, Spain, pp. 363-376.

174 Sanders, D. R., Kim, Y. I. and Stubbs, N. (1992*), "Nondestructive Evaluation of Damage in Composite Structures Using Modal Parameters", Experimental Mechanics, Vol. 32(3), pp. 240-251.

175 Santos, J. V. A., Soares, C. M. M., Soares, C. A. M. and Maia, N. M. M. (2003a), "Análise de Erros na Identificação do Dano em Estruturas Laminadas", VII Congresso de Mecânica Aplicada e Computacional, Universidade de Évora, Portugal (in Portuguese), pp. 95-103.

176 Santos, J. V. A., Soares, C. M. M., Soares, C. A. M. and Maia, N. M. M. (2003b), "Structural Damage Identification: Influence of Model Incompleteness and Errors", Composite Structures, Vol. 62(3-4), pp. 303313.

177 Santos, J. V. A., Soares, C. M. M., Soares, C. A. M. and Maia, N. M. M. (2004), "Modelos de Identificação do Dano com base nas Características Dinâmicas de Estruturas", Métodos Computacionais em Engenharia (in Portuguese).

178 Santos, J. V. A., Soares, C. M. M., Soares, C. A. M. and Maia, N. M. M. (2005), "Structural Damage Identification in Composite Structures using FRF Data", Composite Structures, Vol. 67, pp. 239-249.

179 Santos, J. V. A., Soares, C. M. M., Soares, C. A. M. and Pina, H. L. G. (1999), "Damage Identification of Composite Structures: a Numerical Model", Mechanics of Composite Materials and Structures, Vol. 6, pp. 363-379.

180 Santos, J. V. A., Soares, C. M. M., Soares, C. A. M. and Pina, H. L. G. (2000), "Development of a Numerical Model for the Damage Identification on Composite Plate Structures", Composite Structures, Vol. 48, pp. 59-65.

181 Saravanos, D. A., Birman, V. and Hopkins, D. A. (1994*), "Detection of Delaminations in Composite Beams using Piezoelectric Sensors", Proceedings of the $31^{\text {st }}$ AIAA/ASME/ASCE/AHS/ASC Structures, Structural Dynamics and Materials Conference, pp. 181-191.

182 Savov, K. and Wenzel, H. (2005), "System Identification and Damage Detection using Wavelet Analysis: Applications in Frame Structures", Proceedings of the $1^{\text {st }}$ International Operational Modal Analysis Conference (IOMAC 2005), Copenhagen, Denmark, pp. 511-518.

183 Shi, Z. Y. and Law, S. S. (2005a), "Parameter Identification-Based Damage Detection for Nonlinear Systems", Proceedings of the $1^{\text {st }}$ International Operational Modal Analysis Conference (IOMAC 2005), Copenhagen, Denmark, pp. 503-510. 
184 Shi, Z. Y. and Law, S. S. (2005b), "Parameter Identification-Based Damage Detection for Linear TimeVarying Systems", Proceedings of the $1^{\text {st }}$ International Operational Modal Analysis Conference (IOMAC 2005), Copenhagen, Denmark, pp. 527-534.

185 Shu, D. and Della, C. N. (2004), "Vibrations of Multiple Delaminated Beams", Composite Structures, Vol. 64, pp. 467-477.

186 Sidhu, J. and Ewins, D. J. (1984), "Correlation of Finite Element and Modal Test Studies of a Practical Structure", Proceedings of the $2^{\text {nd }}$ International Modal Analysis Conference (IMAC II), Orlando, Florida, USA, pp. 185-192.

187 Silva, A. J. P. F. (2001), "Propagação de Delaminagem em Compósitos de Matriz Polimérica", PhD Thesis, Instituto Superior Técnico, Technical University of Lisbon, Portugal (in Portuguese).

188 Silva, J. M. M. and Gomes, A. J. M. A. (1990*), "Experimental Dynamic Analysis of Cracked Free-Free Beams", Experimental Mechanics, Vol. 30(1), pp. 20-25.

189 Silva, J. M. M. and Gomes, A. J. M. A. (1991), "Crack Modelling Using Torsional Springs", Actas das Quartas Jornadas de Fractura, Sociedade Portuguesa de Materiais, Instituto Superior Técnico, Technical University of Lisbon, Portugal (in Portuguese).

190 Silva, J. M. M. and Gomes, A. J. M. A. (1994*), "Crack Identification of Simple Structural Elements through the use of Natural Frequency Variations: The Inverse Problem", Proceedings of the $12^{\text {th }}$ International Modal Analysis Conference (IMAC XII), Honolulu, Hawaii, USA, pp. 1728-1735.

191 Simmers Jr., G., Sodano, H., Park, G. and Inman, D. J. (2005), "Impedance-based Structural Health Monitoring to Detect Corrosion", Proceedings of the $23^{\text {rd }}$ International Modal Analysis Conference (IMAC XXIII), Orlando, Florida, USA, paper no. 56.

192 Sohn, H. and Farrar, C. R. (2001b), "Damage Diagnosis using Time Series Analysis of Vibration Signals", Smart Materials and Structures, Vol. 10(3), pp. 446-451.

193 Sohn, H., Farrar, C. R., Hemez, F. M., Shunk, D. D., Stinemates, D. W. and Nadler, B. R. (2003), "A Review of Structural Health Monitoring Literature: 1996-2001", Los Alamos National Laboratory, USA.

194 Sohn, H., Farrar, C. R., Hunter, N. F. and Worden, K. (2001a**), "Structural Health Monitoring using Statistical Pattern Recognition Techniques", Journal of Dynamic Systems Measurement and ControlTransactions of the ASME, Vol. 123(4), pp. 706-711.

195 Sohn, H., Park, G., Wait, J. R., Limback, N. P. and Farrar, C. R. (2004b), "Wavelet-based Signal Processing for Detecting Delamination in Composite Plates", Smart Materials and Structures, Vol. 13(1), pp. 153-160.

196 Sohn, H., Park, H., Law, K. H. and Farrar, C. R. (2005), "Instantaneous Online Monitoring of Unmanned Aerial Vehicles without Baseline Signals", Proceedings of the $23^{\text {rd }}$ International Modal Analysis Conference (IMAC XXIII), Orlando, Florida, USA, paper no. 259.

197 Sohn, H., Wait, J. R., Park, G. and Farrar, C. R. (2004a), "Multi-Scale Structural Health Monitoring for Composite Structures", Proceedings of the $2^{\text {nd }}$ European Workshop on Structural Health Monitoring, Forum am Deutschen Museum, Munich, Germany, pp. 721-729.

198 Spencer Jr., B. F., Sandoval, M. E. R. and Kurata, N. (2004), "Smart Sensing Technology: Opportunities and Challenges", Journal of Structural Control and Health Monitoring, Vol. 11(4), pp. 349-368.

199 Steenackers, G. and Guillaume, P. (2005), "Structural Health Monitoring of the Z-24 Bridge in Presence of Environmental Changes using Modal Analysis", Proceedings of the $23^{\text {rd }}$ International Modal Analysis Conference (IMAC XXIII), Orlando, Florida, USA, paper no. 297.

200 Stubbs, N., Kim, J. T. and Farrar, C. R. (1995*), "Field Verification of a Nondestructive Damage Localization and Severity Estimation Algorithm", Proceedings of the $13^{\text {th }}$ International Modal Analysis Conference (IMAC XIII), Nashville, Tennessee, USA, pp. 210-218.

201 Stubbs, N. and Osegueda, R. (1990a*), "Global Non-Destructive Damage Evaluation in Solids", Modal Analysis: The International Journal of Analytical and Experimental Modal Analysis, Vol. 5(2), pp. 67-79.

202 Stubbs, N. and Osegueda, R. (1990b*), "Global Damage Detection in Solids-Experimental Verification", Modal Analysis: The International Journal of Analytical and Experimental Modal Analysis, Vol. 5(2), pp. 81-97.

$203 \mathrm{Su}, \mathrm{Z}$., Ye, L. and Bu, X. (2002), "Evaluation of Delamination in Laminated Composites based on Lamb Waves Methods: FEM Simulation and Experimental Verification", Proceedings of the $1^{\text {st }}$ European Workshop on Structural Health Monitoring, Ecole Noemale Supérieure, Cachan, Paris, France, pp. 328-335.

204 Sundararaman, S., Adams, D. E. and Rigas, E. J. (2005), "Characterizing Damage in Plates through Beamforming with Sensor Arrays", Proceedings of the $23^{\text {rd }}$ International Modal Analysis Conference (IMAC XXIII), Orlando, Florida, USA, paper no. 249.

205 Sundaresan, M. J., Ghoshal, A. and Schulz, M. J. (2001), "A Continuous Sensor to Measure Acoustic Waves in Plates", Journal of Intelligent Material Systems and Structures, Vol. 12(1), pp. 41-56.

206 Sundaresan, M. J., Grandhi, G., Schulz, M. J. and Kemerling, J. C. (2004), "Monitoring Damage Growth in a Composite Plate using a Continuous Sensor", Proceedings of the $22^{\text {nd }}$ International Modal Analysis Conference (IMAC XXII), Dearborn, Michigan, USA, paper no. 369. 
207 Sundaresan, M. J., Pai, P. F., Ghoshal, A., Schulz, M. J., Ferguson, F. and Chung, J. H. (2001), "Methods of Distributed Sensing for Health Monitoring of Composite Material Structures", Composites: Part A, Vol. 32, pp. 1357-1374.

208 Taylor, S. and Zimmerman, D. C. (2005), "Damage Detection in a Cargo Bay Frame using Ritz Vectors", Proceedings of the $23^{\text {rd }}$ International Modal Analysis Conference (IMAC XXIII), Orlando, Florida, USA, paper no. 355.

209 Testa, R. B. (2005), "Characteristics and Detection of Damage and Fatigue Cracks", Advanced Course on Dynamic Methods for Damage Detection in Structures, CISM (Centre International des Sciences Méchaniques), Udine, Italy.

210 Thien, A. B., Chiamori, H. C., Ching, J. T., Wait, J. R. and Park, G. (2005), "Piezoelectric Active Sensing for Damage Detection in Pipeline Structures", Proceedings of the $23^{\text {rd }}$ International Modal Analysis Conference (IMAC XXIII), Orlando, Florida, USA, paper no. 323.

211 Tippetts, T. and Hemez, F. M. (2005), "Non-Linear Models of Composite Laminates", Proceedings of the $23^{\text {rd }}$ International Modal Analysis Conference (IMAC XXIII), Orlando, Florida, USA, paper no. 10.

212 Toyama, N. and Okabe, T. (2004), "Effects of Tensile Strain and Transverse Cracks on Lamb-Wave Velocity in Cross-Ply FRP Laminates", Journal of Materials Science, Vol. 39, pp. 7365-7367.

213 Tracy, J. J. and Pardoen, G. C. (1989*), "Effect of Delamination on the Natural Frequencies of Composite Laminates", Journal of Composite Materials, Vol. 23, pp. 1200-1215.

214 Uhl, T. and Mendrok, K. (2004), "Overview of Modal Model based Damage Detection Methods", Proceedings of the International Conference on Noise an Vibration Engineering (ISMA 2004), Leuven, Belgium, pp. 361-375.

215 Vanhonacker, P. (1980), "Differential and Difference Sensitivities of Natural Frequencies and Mode Shapes of Mechanical Structures", AIAA Journal, Vol. 18(12), pp. 1511-1514.

216 Vanlanduit, S., Parloo, E., Cauberghe, B., Guillaume, P. and Verboven, P. (2005), "A Robust Singular Value Decomposition for Damage Detection under Changing Operating Conditions and Structural Uncertainties", Journal of Sound and Vibration, Vol. 284, pp. 1033-1050.

217 Vecchio, A. and Van der Auweraer, H. (2001), "An Experimental Validation of a Model-Based Approach in Damage Detection and Validation", Proceedings of the $3^{\text {rd }}$ International Workshop on Structural Health Monitoring, Stanford University, Palo Alto, California, USA, pp. 957-966.

218 Vecchio, A., Van der Auweraer, H., Ferraro, G., Garesci, F. and Petrone, F. (2002), "An Experimental Validation of a Model-Based Approach in Damage Detection and Localization", Proceedings of the $1^{\text {st }}$ European Workshop on Structural Health Monitoring, Ecole Noemale Supérieure, Cachan, Paris, France, pp. 245-252.

219 Vescovo, D. D. and Fregolent, A. (2005), "Assessment of Fresco Detachments through a Non-Invasive Acoustic Method", Journal of Sound and Vibration, Vol. 285, pp. 1015-1031.

220 Wahab, M. M. and De Roeck, G. (1999), "Damage Detection in Bridges using Modal Curvatures: Application to a Real Damage Scenario", Journal of Sound and Vibration, Vol. 226(2), pp. 217-235.

221 Wahl, F., Schmidt, G. and Forrai, L. (1999), "On the Significance of Antiresonance Frequencies in Experimental Structural Analysis", Journal of Sound and Vibration, Vol. 219(3), pp. 379-394.

222 Wang, K., Inman, D. J. and Farrar, C. R. (2005), "Modelling and Analysis of a Cracked Composite Cantilever Beam Vibrating in Coupled Bending and Torsion", Journal of Sound and Vibration, Vol. 284, pp. 23-49.

223 Wei, Z., Yam, L. H. and Cheng, L. (2005), "NARMAX Model Representation and its Application to Damage Detection for Multi-layer Composites", Composite Structures, Vol. 68(1), pp. 109-117.

224 West, W. M. (1984*), "Illustration of the Use of Modal Assurance Criterion to Detect Structural Changes in an Orbiter Test Specimen", Proceedings of the Air Force Conference on Aircraft Structural Integrity, pp. 16.

225 Wilson, E. L., Yuan, M. W. and Dicken, J. M. (1982), "Dynamic Analysis by Direct Superposition of Ritz Vectors", Earthquake Engineering and Structural Dynamics, Vol. 10, pp. 813-821.

226 Woon, C. E. and Mitchell, L. D. (1996a), "Variations in Structural Dynamics Characteristics caused by Changes in Ambient Temperature: I. Experimental", Proceedings of the $14^{\text {th }}$ International Modal Analysis Conference (IMAC XIV), Dearborn, Michigan, USA, pp. 963-971.

227 Woon, C. E. and Mitchell, L. D. (1996b), "Variations in Structural Dynamics Characteristics caused by Changes in Ambient Temperature: II. Analytical", Proceedings of the $14^{\text {th }}$ International Modal Analysis Conference (IMAC XIV), Dearborn, Michigan, USA, pp. 972-980.

228 Worden, K., Manson, G. and Fieller, N. R. J. (2000**), "Damage Detection using Outlier Analysis", Journal of Sound and Vibration, Vol. 229(3), pp. 647-667.

229 Wowk, V. (1991), "Machinery Vibration: Measurement and Analysis", McGraw-Hill.

$230 \mathrm{Wu}$, Z. S., Yang, C. Q., Harada, T. and Ye, L. P. (2005), "Self-Diagnosis of Structures Strengthened with Hybrid Carbon-Fiber Reinforced Polymer Sheets", Smart Materials and Structures, Vol. 14, pp. 39-51. 
231 Yam, L. H., Wei, Z. and Cheng, L. (2004), "Nondestructive Detection of Internal Delamination by Vibration-based Method for Composite Plates", Journal of Composite Materials, Vol. 38(24), pp. 21832198.

232 Yan, A. M., Golinval, J. C., Peeters, B. and De Roeck, G. (2004), "A Comparative Study on Damage Detection of Z24-bridge: One-year Monitoring with Varying Environmental Conditions", Proceedings of the $2^{\text {nd }}$ European Workshop on Structural Health Monitoring Forum am Deutschen Museum, Munich, Germany, pp. 791-799.

233 Yan, A. M., Kerschen, G., De Boe, P. and Golinval, J. C. (2005a), "Structural Damage Diagnosis under Varying Environmental Conditions - Part I: A Linear Analysis", Mechanical Systems and Signal Processing, Vol. 19, pp. 847-864.

234 Yan, A. M., Kerschen, G., De Boe, P. and Golinval, J. C. (2005b), "Structural Damage Diagnosis under Varying Environmental Conditions - Part II: Local PCA for Non-Linear Cases", Mechanical Systems and Signal Processing, Vol. 19, pp. 865-880.

235 Yang, J. N., Lei, Y., Pan, S. and Huang, N. (2003), "Identification of Linear Structures Based on HilbertHuang Transform Part II: Complex Modes", Earthquake Engineering and Structural Dynamics, Vol. 32, pp. 1443-1467.

236 Yoon, M. K., Heider, D., Gillespie, J. W., Ratcliffe, C. P. and Crane, R. M. (2005), "Local Damage Detection using the Two-dimensional Gapped Smoothing Method", Journal of Sound and Vibration, Vol. 279(1-2), pp. 119-139.

237 Yu, L., Yin, T., Zhu, H. P. and Xu, D. Y. (2005), "An Improved Genetic Algorithm for Structural Damage Detection", Proceedings of the $1^{\text {st }}$ International Operational Modal Analysis Conference (IOMAC 2005), Copenhagen, Denmark, pp. 361-368.

238 Zabel, V. (2004), "A Wavelet-Based Damage Detection Indicator for Reinforced Concrete Structures", Proceedings of the $22^{\text {nd }}$ International Modal Analysis Conference (IMAC XXII), Dearborn, Michigan, USA, paper no. 70.

239 Zabel, V. (2005a), "A Wavelet-based Approach for Damage Detection on Civil Engineering Structures", Proceedings of the $23^{\text {rd }}$ International Modal Analysis Conference (IMAC XXIII), Orlando, Florida, USA, paper no. 178.

240 Zabel, V. (2005b), "Application of Wavelet Decompositions' Energy Components to Damage Detection", Proceedings of the $1^{\text {st }}$ International Operational Modal Analysis Conference (IOMAC 2005), Copenhagen, Denmark, pp. 519-526.

241 Zak, A., Krawczuk, M. and Ostachowicz, W. (1999**), "Vibration of a Laminated Composite Plate with Closing Delamination", Proceedings of the $3^{\text {rd }}$ International Conference on Damage Assessment of Structures (DAMAS 99), Dublin, Ireland, pp. 17-26.

242 Zang, C., Friswell, M. I. and Imregun, M. (2003a), "Structural Health Monitoring and Damage Assessment using Measured FRFs from Multiple Sensors, Part I: The Indicator of Correlation Criteria", Proceedings of the $5^{\text {th }}$ International Conference on Damage Assessment of Structures (DAMAS 2003), Southampton, England, UK, pp. 131-140.

243 Zang, C., Friswell, M. I. and Imregun, M. (2003b), "Structural Health Monitoring and Damage Assessment using Measured FRFs from Multiple Sensors, Part II: Decision Making with RBF Networks", Proceedings of the $5^{\text {th }}$ International Conference on Damage Assessment of Structures (DAMAS 2003), Southampton, England, UK, pp. 141-148.

244 Zhang, R., King, R., Olson, L. and Xu, Y. L. (2005), "Dynamic Response of the Trinity River Relief Bridge to Controlled Pile Damage: Modelling and Experimental Data Analysis Comparing Fourier and HilbertHuang Techniques." Journal of Sound and Vibration, Vol. 285, pp. 1049-1070.

245 Zheng, S., Wang, X. and Liu, L. (2004), "Damage Detection in Composite Materials Based upon the Computational Mechanics and Neural Networks", Proceedings of the $2^{\text {nd }}$ European Workshop on Structural Health Monitoring, Forum am Deutschen Museum, Munich, Germany, pp. 609-615.

246 Zhu, H. P. and Xu, Y. L. (2005), "Damage Detection of Mono-Coupled Periodic Structures based on Sensitivity Analysis of Modal Parameters", Journal of Sound and Vibration, Vol. 285, pp. 363-390.

247 Zimmerman, D. C. (2005), "Statistical Confidence using Minimum Rank Perturbation Theory", Mechanical Systems and Signal Processing, Vol. article in press (available online).

248 Zimmerman, D. C., Kaouk, M. and Simmermacher, T. (1995a*), "On the Role of Engineering Insight and Judgement Structural Damage Detection", Proceedings of the $13^{\text {th }}$ International Modal Analysis Conference (IMAC XIII), Nashville, Tennessee, USA, pp. 414-420.

249 Zimmerman, D. C., Simmermacher, T. and Kaouk, M. (1995b*), "Structural Damage Detection using Frequency Response Functions", Proceedings of the $13^{\text {th }}$ International Modal Analysis Conference (IMAC XIII), Nashville, Tennessee, USA, pp. 179-185. 